\title{
Gedenken an den Ersten Weltkrieg in Württemberg: Die Stuttgarter Erinnerungsfeiern von 1919 bis 1933*
}

\author{
Von Sabine Sauter
}

\section{Einführung}

Eine dichte Menschenmenge drängte sich am Totensonntag des Jahres 1933 auf dem herbstlich gefärbten Stuttgarter Waldfriedhof, um dort, wie seit vielen Jahren, des Ersten Weltkriegs und seiner Gefallenen zu gedenken ${ }^{1}$. Die Präsenz der SA und SS in diesem Jahr kündete jedoch von bevorstehenden Veränderungen: Schon wenige Monate später, im Februar 1934, schufen die Nationalsozialisten den ,Heldengedenktag' und setzten damit kurzerhand durch, was während der Weimarer Republik nicht gelungen war: die Festlegung eines reichsweiten Gedenktags für die Gefallenen des Weltkriegs ${ }^{2}$. Dies besiegelte das Ende einer langen Reihe unabhängiger württembergischer Gedenkfeiern, die sich seit 1919 in der Landeshauptstadt Stuttgart zu einer Tradition entwickelt hatten.

Diese württembergische Gedenktradition steht im Mittelpunkt der folgenden Analyse. Der Beitrag untersucht das offizielle Gedenken an den Ersten Weltkrieg in der Zeit von 1919 bis 1933 und legt dar, auf welche Weise die Erfahrung des Kriegs (um)gedeutet und die Erinnerung an ihn geformt wurde ${ }^{3}$. Mit Hinblick auf

"Grundlage dieses Beitrags ist meine im August 2009 unter der Leitung von Prof. Dr. Ute Planert an der Universität Tübingen abgeschlossene Masterarbeit (unveröffentlicht) mit dem Titel: „Die Erinnerung an den Ersten Weltkrieg in Deutschland und Frankreich, 19181933/39. Eine mentalitätsgeschichtliche Untersuchung der öffentlichen Gedenkfeiern in Württemberg und dem Departement Bouches-du-Rhône“. Ich danke Prof. Dr. Ewald Frie und Dr. des. Daniel Menning für ihre Ermunterung zum Verfassen des Beitrags und für ihre freundliche Unterstützung.

${ }^{1}$ Staatsanzeiger für Württemberg vom 15.11.1933.

2 Vgl. hierzu: Fritz SCHELlack, Nationalfeiertage in Deutschland von 1871-1945, Frankfurt a.M. 1990, S. 276-277, 297; Klaus Latzel, Vom Sterben im Krieg: Wandlungen in der Einstellung zum Soldatentod vom Siebenjährigen Krieg bis zum II. Weltkrieg, Warendorf 1988, S. 91.

${ }^{3}$ Damit verfolgt der Beitrag einen erinnerungsgeschichtlichen Ansatz, dessen theoretische Basis die Arbeiten des französischen Soziologen Maurice Halbwachs und dessen Konzeption des ,kollektiven Gedächtnisses' sind. Das ,kollektive Gedächtnis' ist Halbwachs zufolge eine Rekonstruktion vergangener Ereignisse nach den sozialen Bedürfnissen der 
Deutschlands Weg in den Zweiten Weltkrieg wurden solche Umdeutungsprozesse für die Erklärung der paradox erscheinenden Kriegsbegeisterung in der Zwischenkriegszeit herangezogen und als wesentlicher Teil einer mentalen Kriegsvorbereitung gedeutet ${ }^{4}$.

Es erstaunt daher, dass die Gedenkfeiern als wesentlicher Bestandteil der öffentlichen Erinnerungskultur noch nicht ausführlich untersucht wurden. Zwar wurde mit den Gefallenendenkmälern ein Element der Erinnerungskultur bereits zum Forschungsgegenstand zahlreicher Studien, doch die öffentlichen Erinnerungsfeiern, die viel tiefere Erkenntnisse über Deutungsprozesse erwarten lassen, harren in Deutschland noch immer einer eingehenden Analyse ${ }^{5}$. Die föderative Feiertagsregelung der Weimarer Republik ist sicherlich ein Grund für diesen Mangel, da sie detaillierte regionale Studien erfordert ${ }^{6}$. Dabei birgt doch gerade der regionalgeschichtliche Ansatz große Vorteile: Er ermöglicht eine differenzierte Sicht auf die Lebenswelt der zeitgenössischen Akteure, die in der ersten Hälfte des 20. Jahrhunderts in den südlichen Ländern, wie zum Beispiel Württemberg, noch stark regional geprägt war .

Gegenwart; vgl. Maurice Halbwachs, La Mémoire collective, Paris ${ }^{4} 1997$, S. 52; Ders., La Topographie légendaire des Évangiles en Terre Sainte: Étude de mémoire collective, Paris 1941, S. 9. Von einer identitätsstiftenden Funktion speziell des Totengedenkens für die Gegenwart geht auch Reinhart Koselleck aus; vgl. Reinhart Koselleck, Kriegerdenkmale als Identitätsstiftungen der Überlebenden, in: Identität, hg. von Odo MARQUARD/Karlheinz STIERLE, München ${ }^{2} 1996$, S. 255-276, hier S. 256.

${ }^{4}$ Einen Forschungsüberblick zur Frage nach der Bedeutung der Erfahrung und Verarbeitung des Ersten Weltkriegs für die Vorbereitung des Zweiten Weltkriegs gibt Thomas KüHNE, Die nationalsozialistischen Vernichtungskriege im kulturellen Kontinuum des 20. Jahrhunderts. Forschungsprobleme und Forschungstendenzen der Gesellschaftsgeschichte des Zweiten Weltkriegs. Zweiter Teil, in: Archiv für Sozialgeschichte 40 (2000) S. 440-486, hier v.a. S. 442-451. Zentral hierzu auch: George L. Mosse, Gefallen für das Vaterland: nationales Heldentum und namenloses Sterben, Stuttgart 1993, S. 222-223; Ders., Über Kriegserinnerung und Kriegsbegeisterung, in: Kriegsbegeisterung und mentale Kriegsvorbereitung, hg. von Marcel van der Linden/Gottfried Mergner, Berlin 1991, S. 27-36, hier S. 27-32; Richard Bessel, Kriegserfahrungen und Kriegserinnerungen. Nachwirkungen des Ersten Weltkrieges auf das politische und soziale Leben der Weimarer Republik, in: ebd., S.125140, hier S. 138-139; Latzel (wie Anm. 2) S. 80-83.

${ }^{5}$ Die zahlreichen Studien zu den Kriegerdenkmälern befassen sich allenfalls am Rande mit den in ihrem Umfeld abgehaltenen Gedenkfeiern; vgl. z.B. Meinhold Lurz, Kriegerdenkmäler in Deutschland, Bd. 4: Weimarer Republik, Heidelberg 1985. Zur Bedeutung von Gedenktagen vgl. Dietmar Schiller, Politische Gedenktage in Deutschland - Zum Verhältnis von öffentlicher Erinnerung und politischer Kultur, in: Aus Politik und Zeitgeschichte 43 (1993) S. 32-39, hier S. 32-33.

${ }^{6}$ Vgl. Schellack (wie Anm.2) S.133-135. Ein Überblick über regionalgeschichtliche Arbeiten zum Ersten Weltkrieg bis 1994 bietet Gerd Krumeich, Kriegsalltag vor Ort. Regionalgeschichtliche Neuerscheinungen zum Ersten Weltkrieg in Deutschland, in: Neue politische Literatur 39 (1994) S. 187-202.

7 Vgl. hierzu: Dieter Langewiesche, Nation, Nationalismus, Nationalstaat in Deutschland und Europa, München 2000, S.55-56, 66-78; Alon Confino, Konzepte von Heimat, 
Das Quellenkorpus des Beitrags basiert auf regionalen Zeitungsberichten. Die Presse als das Massenmedium der Zwischenkriegszeit war dabei selbst an den Konstruktionsprozessen von Erinnerung beteiligt ${ }^{8}$. Durch ihre Berichterstattung über die Stuttgarter Gedenkfeiern wirkte sie als wichtiges kommunikatives Bindeglied zwischen der Landeshauptstadt und den umliegenden Städten und Gemeinden. Die grundlegend politische Ausrichtung des Pressewesens wurde bei der Auswahl der Zeitungen und bei der Analyse der Artikel berücksichtigt. Systematisch ausgewertet wurden Presseorgane der vier stärksten politischen Parteien in Württemberg9 : die „Schwäbische Tagwacht“ als Blatt der SPD, das „Deutsche Volksblatt“ als Zeitung des Zentrums, das „Neue Stuttgarter Tagblatt“ sowie die „Württemberger Zeitung“ als Presseorgane der Volkspartei/DDP und schließlich die „Schwäbische Tageszeitung“ als Blatt des Bauernbunds, der wichtigsten konservativen Partei Württembergs. Offizielle Zeitungen wie etwa der „Staatsanzeiger für Württemberg“ wurden ergänzend hinzugezogen. Bereichert wurde dieser Quellengrundstock durch Akten zu den Erinnerungsfeiern aus dem Hauptstaatsarchiv Stuttgart.

\section{Gesetzgebung und Organisation der württembergischen Gedenkfeiern}

Im Kern der öffentlichen Erinnerungskultur des Ersten Weltkriegs stehen Gedenktage für die Gefallenen. Die Versuche, einen reichsweiten ,Volkstrauertag، oder ,Gefallenengedenktag' in der Weimarer Zeit festzulegen, scheiterten infolge der unklaren Kompetenzverteilung zwischen Reich und Ländern sowie aufgrund von Auseinandersetzungen um die inhaltliche Deutung eines solchen Gedenk$\operatorname{tags}^{10}$. In Württemberg wurden seit 1919, weitgehend unberührt von den Diskussionen auf Reichsebene und zunächst ohne gesetzliche Grundlage öffentliche Gefal-

Region, Nation und Staat in Württemberg von der Reichsgründungszeit bis zum Ersten Weltkrieg, in: Föderative Nation. Deutschlandkonzepte von der Reformation bis zum Ersten Weltkrieg, hg. von Dieter Langewiesche, München 2000, S. 345-359, hier S. 353.

8 Zum Pressewesen in diesem Abschnitt vgl. Theodor STEIN, Südwestdeutsche Zeitungsgeschichte. Ein Überblick über die Anfänge bis zum Jahr 1933, in: Von der Preßfreiheit zur Pressefreiheit. Südwestdeutsche Zeitungsgeschichte von den Anfängen bis zur Gegenwart, hg. von der WLB, Stuttgart 1983, S.21-100, hier S.79-82; Reinhold Weber, Bürgerpartei und Bauernbund in Württemberg: konservative Parteien im Kaiserreich und in Weimar (1895-1933), Düsseldorf 2004, S. 204-205.

9 Vgl. hierzu: Paul SAUer, Württemberg in der Weimarer Republik, in: Handbuch der baden-württembergischen Geschichte, Bd.4: Die Länder seit 1918, hg. von Hansmartin Schwarzmaier/Meinrad Schaab, Stuttgart 2003, S.73-129; Willi Boelcke, Sozialgeschichte Baden-Württembergs 1800-1989: Politik, Gesellschaft, Wirtschaft, Stuttgart 1989, S. 305-308.

${ }^{10}$ Vgl. hierzu: Thomas-Peter Petersen, Die Geschichte des Volkstrauertages, Kassel 21999, S. 9-16; Schellack (wie Anm. 2) S. 133-134; Hans Hattenhauer, Deutsche Nationalsymbole. Geschichte und Bedeutung, Köln ${ }^{3} 1998$, S. 124-145. 
lenengedenkfeiern veranstaltet ${ }^{11}$. Von 1920 bis 1926 veranstaltete die Stadt Stuttgart relativ regelmäßig jeweils an einem der letzten Sonntage im Oktober eine Gedenkfeier ${ }^{12}$, bei denen in manchen Jahren auch Vertreter der württembergischen Behörden anwesend waren ${ }^{13}$. Die württembergische Staatsregierung scheint in dieser ersten Phase nur in den Jahren 1924 und 1925 selbst aktiv an der Organisation einer Gedenkfeier beteiligt gewesen zu sein: Als die Reichsregierung aus Anlass des 10. Jahrestags der Kriegserklärung eine deutschlandweite Feier für den 3. August 1924 plante $^{14}$, organisierte auch das württembergische Staatsministerium mit Unterstützung der Stadtverwaltung eine Gedenkveranstaltung ${ }^{15}$. Im Januar des folgenden Jahres 1925 verfügte der Reichsinnenminister auf Anfrage des, Volksbundes Deutsche Kriegsgräberfürsorge` (Volksbund) per Erlass, die Landesregierungen sollten am sechsten Sonntag vor Ostern (Invocavit) eine Trauerfeier ausrichten ${ }^{16}$. Die württembergische Regierung und die Stadt Stuttgart veranstalteten daraufhin in Kooperation mit dem Volksbund eine solche Feier in Stuttgart ${ }^{17}$.

Während auf Reichsebene weiterhin verschiedene Terminvorschläge diskutiert wurden ${ }^{18}$, bahnte sich in Württemberg eine davon unabhängige Lösung an: Eine Arbeitsgemeinschaft von mehreren Veteranenverbänden und Militärvereinen richtete am 10. Juni 1926 ein Schreiben an das württembergische Staatsministerium mit der Bitte, für Württemberg einen Gedenktag für die Weltkriegstoten „im Spätherbst (Anfang November) zu bestimmen und ihn als gesetzlichen Feiertag zu erklären“19. Die Stellungnahmen des Evangelischen Oberkirchenrats ${ }^{20}$ und der katholischen Kirche ${ }^{21}$ wurden eingeholt und auch der Landesverband des Volksbundes meldete

11 Schwäbische Tagwacht vom 22.11.1919 und vom 24.11.1919; Stuttgarter Neues Tagblatt vom 24.11.1919 (Morgen- und Abendausgabe).

12 Belegt für die Jahre 1920-1922 sowie 1925-1926: Schwäbische Tagwacht vom 1.11.1920; Schwäbische Tageszeitung vom 2.11.1920; Stuttgarter Neues Tagblatt vom 1.11.1920 (Abendausgabe); Württemberger Zeitung vom 24.10.1921, vom 23.10.1922 und vom 19.10.1925; Staatsanzeiger für Württemberg vom 26.10.1926.

13 Z.B. nahm Staatspräsident Hieber in den Jahren 1921 und 1922 an der Feier der Stadt Stuttgart teil: Württemberger Zeitung vom 24.10.1921 und vom 23.10.1922.

14 Vgl. Schellack (wie Anm. 2) S. 205-206.

15 Staatsanzeiger für Württemberg vom 30.7.1924.

16 Vgl. hierzu: Schellack (wie Anm. 2) S. 231; Lurz (wie Anm. 5) S. 417; Petersen (wie Anm. 10) S. 16.

17 Staatsanzeiger für Württemberg vom 21.2.1925; Süddeutsche Zeitung vom 28.2.1925.

18 Vgl. hierzu: Schellack (wie Anm. 2) S. 235-239; Lurz (wie Anm. 5) S. 413-422; PeTERSEN (wie Anm. 10) S. 9-13.

19 HStA Stuttgart E 151/01 Bü 2919: Antrag (Abschrift) der Arbeitsgemeinschaft (Württembergischer Kriegerbund, Württembergischer Offiziersbund, Arbeitsgemeinschaft der Regimentsvereinigungen, Landesverband Württemberg der Marine-Vereine) vom 10.6.1926.

${ }^{20}$ HStA Stuttgart E 151/01 Bü 2919: Schreiben (Abschrift) des Evangelischen Oberkirchenrats an das Württembergische Kultministerium vom 22.6.1926.

${ }^{21}$ HStA Stuttgart E 151/01 Bü 2919: Schreiben des Württembergischen Kultministeriums an das Ministerium des Innern vom 14.7.1926. 
sich $\mathrm{zu}$ Wort $^{22}$. Sie alle einigten sich auf den letzten Sonntag des Kirchenjahres (Totensonntag) als geeigneten Termin, der dann vom württembergischen Staatsministerium mit Beschluss vom 7. August 1926 als Gefallenengedenktag festgelegt wurde ${ }^{23}$.

Dieser Alleingang Württembergs führte zu einem Konflikt mit dem Bundesvorstand des Volksbundes in Berlin: Im Februar 1928 bat der Volksbund die württembergische Regierung vergeblich um Unterstützung einer von ihm organisierten Gedenkveranstaltung ${ }^{24}$. Daraufhin beschwerte sich der Bundesvorstand in einem Schreiben bei der württembergischen Regierung und unterstellte ihr mangelnde Wertschätzung des Gedenkens an die Gefallenen ${ }^{25}$. Diese Anschuldigung wurde im Staatsministerium als „Unverschämtheit“ ${ }^{26}$ empfunden. Trotz raschen Vermittlungsversuchen des württembergischen Landesverbandes ${ }^{27}$ konnte die Auseinandersetzung erst zwei Jahre später beigelegt werden ${ }^{28}$. Das Beispiel dieses Zerwürfnisses verdeutlicht einerseits die Heterogenität des Volksbundes, andererseits die geringe Bedeutung dieses Verbandes für die öffentlichen Gefallenengedenkfeiern in Stuttgart ${ }^{29}$.

Die gesetzliche Festlegung des württembergischen Trauertags auf den Totensonntag läutete eine neue Phase der Gedenkfeiern ein. In der Zeitspanne von 1927 bis 1933 planten die Stadtverwaltung Stuttgart und die württembergische Staatsregierung nun gemeinsam eine jährliche Gedächtnisfeier: Im ersten Jahr fand die Feier am Vorabend des Totensonntags in der Rotebühlkaserne und im Hof des Neuen Schlosses in Stuttgart statt ${ }^{30}$. Ab dem Herbst 1928 organisierten Stadtverwaltung und Staatsregierung dann eine Gedenkfeier am Totensonntag selbst, die immer um 15 Uhr auf dem Stuttgarter Waldfriedhof stattfand ${ }^{31}$. Die Oberämter erhielten in

${ }^{22}$ HStA Stuttgart E 151/01 Bü 2923: Schreiben des ersten Vorsitzenden des Landesverbandes Württemberg des Volksbundes, Hieber, an das Ministerium des Innern vom 25.6.1926.

${ }^{23}$ Staatsanzeiger für Württemberg vom 20.10.1926; vgl. auch Schellack (wie Anm.2) S. 204.

${ }^{24}$ HStA Stuttgart E 151/01 Bü 2923: Schreiben (Abschrift) des Volksbundes in Berlin an das Württembergische Staatsministerium vom 4.2.1928 und Antwort des Staatspräsidenten am 7.2.1928.

${ }^{25}$ HStA Stuttgart E 151/01 Bü 2923: Schreiben (Abschrift) des Volksbundes in Berlin an die Regierung in Stuttgart vom 17.2.1928.

${ }^{26}$ HStA Stuttgart E 151/01 Bü 2923: Aktenvermerk vom 28.2.1928.

${ }^{27}$ HStA Stuttgart E 151/01 Bü 2923: Schreiben des Landesverbands Württemberg des Volksbundes an den Volksbund in Berlin vom 12.3.1928.

${ }^{28}$ HStA Stuttgart E 130b Bü 3845: Schreiben des Württembergischen Innenministeriums an das Staatsministerium vom 9.2.1930.

${ }^{29}$ Im Gegensatz zur Rolle des Volksbundes auf Reichsebene, die von Petersen als zentral bewertet wird; vgl. Petersen (wie Anm.10) S. 16.

30 Staatsanzeiger für Württemberg vom 14.11.1927 und vom 21.11.1927.

31 Staatsanzeiger für Württemberg vom 3.11.1928, 2.11.1929, 18.11.1930, 7.11.1931, 1.11.1932 und vom 15.11.1933. 
diesen Jahren in der Regel die Anweisung, in ihren jeweiligen Städten und Gemeinden ebenfalls öffentliche Gedenkfeiern abzuhalten ${ }^{32}$. Das Staatsministerium ordnete an, am Totensonntag die staatlichen Gebäude mit den Landes- oder Reichsfarben entweder halbmast oder mit Trauerflor versehen zu beflaggen ${ }^{33}$. Auch die Bevölkerung wurde aufgerufen, die übrigen Gebäude auf die gleiche Art zu schmücken $^{34}$. Die Kirchen würdigten diesen Tag, indem sie ein allgemeines Trauergeläut veranlassten und in ihren Gottesdiensten der Gefallenen gedachten ${ }^{35}$. Das Kultministerium gab bekannt, es sei in den Schulen am Vortag des Totensonntags „in ernster Weise auf die Bedeutung des Gedenktages hinzuweisen “36. Es fällt auf, dass die Kriegsveteranen und ihre Verbände nur sporadisch an der Organisation der Gedenkfeiern beteiligt waren. Der Impuls, der schließlich zur gesetzlichen Festlegung des Volkstrauertages in Württemberg führte, ging zwar von Veteranenverbänden aus, im Übrigen beanspruchten sie aber keine Autorität für diesen Gedenktag ${ }^{37}$.

\section{Der Stuttgarter Waldfriedhof als Erinnerungsort}

Der wichtigste württembergische Erinnerungsort des Ersten Weltkriegs war in der Weimarer Zeit ohne Zweifel der Stuttgarter Waldfriedhof ${ }^{38}$ : Viele der im Krieg gefallenen württembergischen Soldaten wurden auf dem eigens dort angelegten Ehrenfeld bestattet ${ }^{39}$ und die Mehrzahl der offiziellen Gedenkfeiern des Ersten Weltkriegs fand auf dem Waldfriedhof $\operatorname{statt}^{40}$. Dort wurde außerdem auch das zen-

32 Belegt für die Jahre 1929-1932: HStA Stuttgart E 151/01 Bü 2920: Schreiben (Abschrift) des Württembergischen Innenministeriums an die Oberämter vom 15.11.1929, 12.11.1930 und vom 7.11.1932; HStA Stuttgart E 151/01 Bü 2923: Schreiben (Abschrift) vom 12.11.1931.

33 Belegt für die Jahre 1928 und 1929: Staatsanzeiger für Württemberg vom 14.11.1928 und vom 14.11.1929.

34 Ebd.

35 Ebd.; Süddeutsche Zeitung vom 21.10.1930.

${ }^{36}$ Belegt für die Jahre 1927, 1931 und 1932: Schwäbische Tageszeitung vom 18.11.1927; Staatsanzeiger für Württemberg vom 7.11.1931 und vom 1.11.1932.

${ }^{37} \mathrm{Im}$ deutlichen Gegensatz etwa zu den Veteranen in Frankreich; vgl. Antoine Prost, Les Anciens Combattants et la société française, 1914-1939, Bd.3: Mentalités et idéologies, Paris 1977, S. 63-64.

38 Pierre Nora zufolge sind Erinnerungsorte immer zugleich materielle, symbolische und funktionale Orte und haben als Verdichtungspunkte des kollektiven Gedächtnisses für die betreffende Gruppe eine identitätsstiftende Funktion. In diesem Sinne handelt es sich bei dem Stuttgarter Waldfriedhof sicherlich um einen klassischen Erinnerungsort; vgl. Pierre Nora, Entre Mémoire et Histoire, in: Les lieux de mémoire, hg. von Ders., Paris ${ }^{2} 1997$, S. 23-43.

39 Vgl. Ulrich Müller, Der Stuttgarter Waldfriedhof und das Kriegerehrenfeld des Ersten Weltkriegs, in: Schwäbische Heimat 46 (1995) S. 358-365, hier S. 358-359.

40 Ausnahmen sind die Gedenkfeiern am 3.8.1924 und am 20.11.1927, die auf dem Stuttgarter Schlosshof stattfanden. 
trale Stuttgarter Gefallenendenkmal aufgestellt ${ }^{41}$. Den Gedanken, ein solches Denkmal zu errichten, hatte man in Stuttgart spätestens im Sommer 1921 gefasst $^{42}$. Ein Denkmalsausschuss wurde ins Leben gerufen, der vier Standorte diskutierte: ein Platz auf einer Anhöhe an der Stadtgrenze, die Innenstadt, zum Beispiel beim Schillerdenkmal, die Schlossanlagen und schließlich das Ehrenfeld auf dem Waldfriedhof ${ }^{43}$. Die Mehrheit entschied sich für den Waldfriedhof als den geeignetsten $\mathrm{Ort}^{44}$. Im Sommer 1922 wurde ein Wettbewerb um die Gestaltung des Denkmals ausgeschrieben $^{45}$, den Professor Dr. Paul Bonatz für sich entschied ${ }^{46}$. Sein Ehrenmal ist in Form einer Apsis mit anschließendem Ehrenhof gestaltet ${ }^{47}$. Im hinteren Drittel des Ehrenhofs steht mittig ein großes Hochkreuz, auf gleicher Höhe erhebt sich in seinem vordersten Abschnitt ein großer, steinerner Altar, der mit dem Eisernen Kreuz und den württembergischen Hirschstangen geschmückt ist. Die Einweihung des Ehrenmals, bei der u. a. auch Oberbürgermeister Lautenschlager und Staatspräsident Hieber vertreten waren, fand am 15. Juli $1923 \mathrm{statt}^{48}$.

Neben dem Ehrenmal war auch der Platz um das bereits bestehende große Friedhofskreuz eine weitere wichtige Gedenkstätte, denn dort fanden die Stuttgarter Gedenkfeiern in der Zeit vor $1923^{49}$ und dann wieder ab dem Jahr 1928 statt. Ein Bericht über die Feier von 1928 verweist darauf, dass der Platz am Ehrenmal schlicht zu klein für die Menschenmenge gewesen wäre ${ }^{50}$. Für die ab 1928 abgehaltenen Gedenkfeiern wurde der Platz beim großen Friedhofskreuz eigens geschmückt, wie Fotos und ein detaillierter Plan der Feier aus dem Jahr 1928 zeigen (Abb. 1-3): Vor dem großen Friedhofskreuz standen auf hohen Säulen zwei Schalen, in denen Feuer brannte. Gegenüber dem Kreuz wurde ein schwarzer Katafalk errichtet, der an drei Seiten von Lanzen umgeben war und mit Blumen und Kränzen geschmückt wurde. Auf dem Katafalk lagen ein Stahlhelm und vier gekreuzte Bajonette.

${ }^{41}$ Staatsanzeiger für Württemberg vom 16.7.1923.

${ }^{42}$ Vgl. Spendenaufruf in der Württemberger Zeitung vom 11.8.1921.

43 Württemberger Zeitung vom 20.10.1922.

${ }^{44}$ Ebd.

45 Württemberger Zeitung vom 11.8.1922. Nach Berichten der Württemberger Zeitung vom 20.10.1922 waren Ende Oktober 1922 bereits um die 150 Bewerbungen eingegangen sowie 600.000 Mark an Spendengeldern gesammelt worden.

${ }^{46}$ Vgl. Müller, Waldfriedhof (wie Anm. 39) S. 361.

47 Zur Gestaltung des Ehrenmals vgl.: Müller, Waldfriedhof (wie Anm. 39) S. 361; Lurz (wie Anm. 5) S. 225; HStA Stuttgart E 130b Bü 3843: Grundriss des Ehrenfeldes mit dem Ehrenmal auf dem Waldfriedhof in Stuttgart. Vgl. außerdem: Beschreibung von Dr. Ing. Alfred Schmidt, Regierungsbaumeister Stuttgart, in: Stuttgarter Neues Tagblatt vom 14.7.1923 (Morgenausgabe); Schwäbische Tagwacht vom 16.7.1923.

48 Staatsanzeiger für Württemberg vom 16.7.1923.

${ }^{49}$ Belegt für die Jahre 1921 und 1922: Württemberger Zeitung vom 24.10.1921 und vom 23.10.1922.

${ }^{50}$ HStA Stuttgart E 130b Bü 3846: Bericht über die Feier von 1928. 


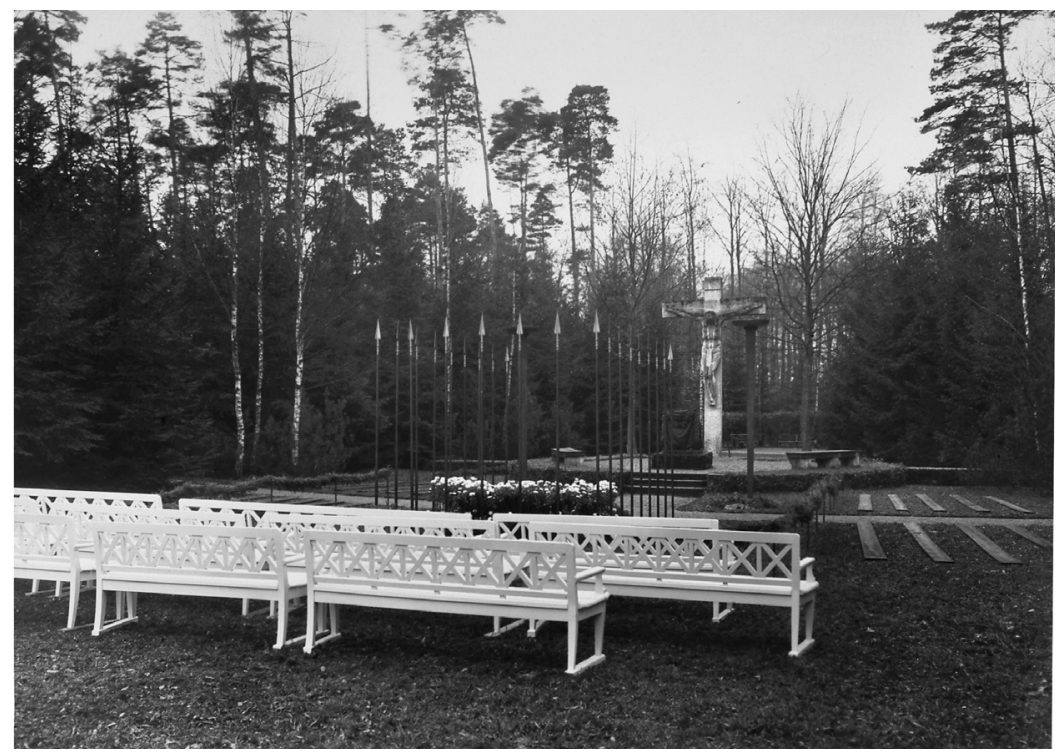

Abb. 1: Foto der Gefallenengedenkfeier in Stuttgart im November 1928 (Vorlage: HStA Stuttgart E 130b Bü 3846).



Abb. 2: Foto der Gefallenengedenkfeier in Stuttgart im November 1928 (Vorlage: HStA Stuttgart E 130b Bü 3846). 




Abb. 3: Skizze über die Aufstellung bei der Gedenkfeier im November 1928 auf dem Waldfriedhof in Stuttgart am großen Friedhofskreuz (Vorlage: HStA Stuttgart E 130b Bü 3846). 


\section{Gedenkzeremonien und ihre Teilnehmer}

Erinnerungsorte wie der Stuttgarter Waldfriedhof entfalten ihre identitätsstiftende Funktion allein im Kontext der sie begleitenden Gedenkzeremonien. Diese setzen sich aus ritualisierten Handlungsabläufen zusammen und variieren deshalb über die Jahre hinweg sehr wenig ${ }^{51}$. Der überwiegende Teil der öffentlichen Gedenkfeiern für den Ersten Weltkrieg in Stuttgart umfasste folgende Komponenten: Die Feiern waren normalerweise öffentlich, prinzipiell jedem zugänglich und fanden unter freiem Himmel statt ${ }^{52}$. Die Gedenkzeremonie im engeren Sinn bestand aus einem relativ schematischen Programm, in dessen Mittelpunkt eine musikalisch umrahmte Gedächtnisrede stand. Nur in wenigen Fällen gab es mehr als eine Rede. Die Musikstücke und Lieder sind zwar nur bruchstückhaft überliefert, doch Lieder mit religiösem Charakter und Trauermärsche scheinen besonders häufig gespielt worden zu sein ${ }^{53}$. Einen herausragenden Platz nahm offenbar das, Lied des guten Kameraden' ein $^{54}$ : Es wurde oft gespielt, meist direkt im Anschluss an die Gedenkrede $^{55}$ und erhielt eine besondere symbolische Bedeutung, wenn sich die Versammelten zu seinen Klängen „zur Ehrung der Toten“ erhoben ${ }^{56}$, ihr Haupt entblößten ${ }^{57}$ oder die Fahnen senkten ${ }^{58}$. Zum Ablauf der Feier gehörte außerdem noch das Schmücken der Soldatengräber und des Ehrenmals, meistens mit Kränzen $^{59}$.

Die ab 1928 abgehaltenen Feiern waren straff organisierte Großveranstaltungen: Alle Vereinigungen und Verbände, die geschlossen an der Feier teilnehmen wollten, mussten sich im Vorfeld bei der Schutzpolizei registrieren ${ }^{60}$. Für die Angehörigen

51 Vgl. hierzu: Reinhart Koselleck, Einleitung, in: Der politische Totenkult. Kriegerdenkmäler in der Moderne, hg. von Reinhart Koselleck/Michael Jeismann, München 1994, S. 9-20, hier S. 9-10; Schiller (wie Anm. 5) S. 32.

52 Eine Ausnahme war das am 1.3.1925 veranstaltete Trauerkonzert in der Stuttgarter Liederhalle, zu dem der Einlass beschränkt war: Staatsanzeiger für Württemberg vom 21.2.1925.

${ }^{53}$ HStA Stuttgart E 151/01 Bü 2923: Vortragsfolge der Jahre 1927, 1928, 1929, 1932; außerdem für das Jahr 1931: Amtsblatt der Stadt Stuttgart vom 21.11.1931.

${ }^{54}$ Der, Gute Kamerad' war das im Ersten Weltkrieg meistgesungene Lied der deutschen Soldaten an der Front und erklang in der Weimarer Republik häufig bei Gedenktagen für die Toten des Ersten Weltkriegs, insofern bilden die württembergischen Feiern keine Ausnahme; vgl. Kurt Oesterle, Die heimliche deutsche Hymne, in: Schwäbisches Tagblatt vom 15.11.1997; http://www.bdzv.de/kurt_oesterle.html (31.1.2013).

55 Gespielt in den Jahren 1926-1929 und 1931-1932; außer 1926 immer direkt nach der Gedenkrede: Schwäbische Kronik des Schwäbischen Merkur vom 25.10.1926; Amtsblatt der Stadt Stuttgart vom 21.11.1931; HStA Stuttgart E 151/01 Bü 2923: Vortragsfolge der Lieder 1927, 1928, 1929 und 1932.

56 Staatsanzeiger für Württemberg vom 2.3.1925.

57 Staatsanzeiger für Württemberg vom 25.11.1929.

${ }^{58}$ Deutsches Volksblatt vom 25.11.1929.

59 Schwäbische Tagwacht vom 24.11.1919 und vom 1.11.1920; Süddeutsche Zeitung vom 28.2.1925; Württemberger Zeitung vom 25.11.1929.

${ }^{60}$ Staatsanzeiger für Württemberg vom 3.11.1928 und vom 2.11.1929. 
der Gefallenen, „welche die Feier nicht mit einer geschlossenen Vereinigung besuch[t]en“, wurden „besondere Einlasskarten mit Vortragsordnung ausgegeben “61. Um den Transport der zahlreichen Besucher, vor allem der gehbehinderten Kriegsbeschädigten zu erleichtern, wurden zusätzliche Autobusse bereitgestellt ${ }^{62}$. Die eigentliche Gedenkzeremonie dauerte dann laut eines Berichts von 1928 ungefähr 40 Minuten $^{63}$. Am Ende des Programms zogen in der Regel alle Teilnehmer gemeinsam zum Ehrenfeld mit dem Ehrenmal ${ }^{64}$.

Die Gedenkfeiern erfüllten offenbar ein starkes soziales Bedürfnis: Die Quellen nennen ungefähr 8.000 bis 10.000 Besucher jährlich ${ }^{65}$. Der Großteil von ihnen besuchte die Gedenkfeiern privat und blieb somit anonym. Diejenigen Besucher, die in einer öffentlichen Funktion an den Feierlichkeiten teilnahmen, vor allem die Vertreter der Behörden und des Militärs, wurden hingegen in den Presseberichten oft namentlich genannt ${ }^{66}$. Häufige Erwähnung fanden zum Beispiel der Stuttgarter Oberbürgermeister und der württembergische Staatspräsident ${ }^{67}$ sowie die Reichswehr und die Schutzpolizei ${ }^{68}$. An Verbänden und Vereinen wurden oft verschiedene Veteranenverbände angeführt ${ }^{69}$, zum Beispiel der sozialdemokratische ,Reichsbund der Kriegsbeschädigten und ehemaliger Kriegsteilnehmer (Reichsbund $)^{70}$, verschiedene Organisationen der Kriegshinterbliebenen und Kriegsbe-

61 Amtsblatt der Stadt Stuttgart vom 20.11.1928.

62 Deutsches Volksblatt vom 23.11.1929.

63 HStA Stuttgart E 130b Bü 3846: Bericht über die Gedenkfeier des Jahres 1928.

64 Z.B.: Staatsanzeiger für Württemberg vom 26.11.1928 und vom 24.11.1930; Amtsblatt der Stadt Stuttgart vom 21.11.1931.

65 Das Amtsblatt der Stadt Stuttgart vom 27.11.1928 spricht von 8.000 bis 10.000 Teilnehmern, das Deutsche Volksblatt vom 22.11.1932 erwähnt 9.500 Personen, die von der Straßenbahn befördert wurden.

66 Eine Teilnehmerliste des Jahres 1928 gibt exemplarisch genauere Auskunft über die Teilnehmer: HStA Stuttgart E 130b Bü 3846: Anmeldeliste für die Gefallenen-Gedenkfeier am 25.11.1928.

67 Staatsanzeiger für Württemberg vom 26.11.1928, 25.11.1929, 24.11.1930 und vom 23.11.1931; Deutsches Volksblatt vom 21.11.1932.

68 Württemberger Zeitung vom 19.10.1925; Schwäbischer Merkur vom 21.11.1927; Staatsanzeiger für Württemberg vom 26.11.1928, 25.11.1929, 24.11.1930 und vom 23.11.1931; Deutsches Volksblatt vom 25.11.1929; Schwäbische Tageszeitung vom 21./22.11.1932. Bei der Feier im Jahr 1928 stellten die Reichswehr und die Schutzpolizei Abordnungen, die links und rechts des Katafalks angeordnet waren, siehe Abb. 3: Skizze der Gedenkfeier 1928 auf dem Waldfriedhof.

$69 \mathrm{Zu}$ den Veteranenverbänden im Folgenden vgl. James M. DieHL, Germany: Veterans' politics under Three flags, in: The war generation. Veterans of the First World War, hg. von Stephen R. Ward, Port Washington/London 1975, S. 135-186.

70 Schwäbische Tagwacht vom 22.11.1919; Stuttgarter Neues Tagblatt vom 24.11.1919 (Morgen- und Abendausgabe); HStA Stuttgart E 130b Bü 3846: Anmeldeliste für die Gefallenen-Gedenkfeier am 25.11.1928. Der Reichsbund organisierte in zeitlicher Nähe zum Totensonntag private Gedenkfeiern, vgl.: HStA Stuttgart E 151/01 Bü 2923: Einladung des Reichsbunds der Kriegsbeschädigten, Kriegsteilnehmer und Kriegshinterbliebenen, Orts- 
schädigten sowie Regiments-, Militär- und Offiziersvereine ${ }^{71}$. Mit dem antirepublikanischen ,Stahlhelm - Bund der Frontsoldaten' und dem ,Jungdeutschen Orden ${ }^{c}$ waren auch Verbände paramilitärischen Charakters vertreten ${ }^{72}$. Zu ihnen zählte auch das von den Sozialdemokraten im Februar 1924 gegründete, Reichsbanner Schwarz-Rot-Gold, Bund der republikanischen Frontsoldaten ${ }^{673}$.

An der Durchführung des Programms, bestehend aus Gedenkrede und Musik, waren nur wenige der Besucher beteiligt: Für den musikalischen Teil der Gedenkfeiern sorgten meist die Musikkapelle des 1. Grenadierbataillons des 13. Reichswehrinfanterieregiments ${ }^{74}$ und der, Vaterländische Gesangverein Ehrenfeld ${ }^{67}$. Die Gedenkworte bildeten das Herzstück der gesamten Feier, denn sie ermöglichten es, sinnstiftend über den Ersten Weltkrieg zu sprechen und damit seine Deutung zu beeinflussen ${ }^{76}$. Aufgrund dieser herausragenden Bedeutung war die Rednerrolle umkämpft, worauf folgender Kommentar des „Deutschen Volksblatts“ zum Totensonntag aus dem Jahr 1930 hinweist: „Das deutsche Volk ist nicht einmal einig vor den Denkmälern für die Gefallenen. Diese sind geradezu babylonische Türme in jeder einzelnen Gemeinde. Tagelang vorher streitet man sich, aus welcher Partei oder Gruppe der Sprecher der Gedächtnisrede genommen werden soll.“"77 In Stuttgart wurden mit dieser wichtigen Aufgabe fast ausschließlich Geistliche betraut,

gruppe Stuttgart, an das Württembergische Innenministerium vom 13.11.1928 und vom 1.11.1929.

71 Z.B. Schwäbische Tageszeitung vom 2.11.1920 und vom 21./22.11.1932; Staatsanzeiger für Württemberg vom 21.11.1927, 26.11.1928, 25.11.1929, 24.11.1930 und vom 23.11.1931.

72 Vgl. hierzu: Dienl (wie Anm. 69) S. 159-169; Benjamin Ziemann, Die Erinnerung an den Ersten Weltkrieg in den Milieukulturen der Weimarer Republik, in: Kriegserlebnis und Legendenbildung. Das Bild des „modernen“ Krieges in Literatur, Theater, Photographie und Film, Bd.1, hg. von Thomas F. Schneider, Osnabrück 1999, S. 249-270, hier S. 252; außerdem: Schwäbische Tagwacht vom 21.11.1927; Staatsanzeiger für Württemberg vom 26.11.1928 und vom 25.11.1929; HStA Stuttgart E 130b Bü 3846: Anmeldeliste für die Gefallenen-Gedenkfeier am 25.11.1928.

${ }^{73}$ Vgl. hierzu: Dienl (wie Anm.69) S. 170-171; Benjamin Ziemann, Republikanische Kriegserinnerung in einer polarisierten Öffentlichkeit. Das Reichsbanner Schwarz-RotGold als Veteranenverband der sozialistischen Arbeiterschaft, in: Historische Zeitschrift 267 (1998) S. 357-398, hier S. 366-370; Carsten Kohlmann, Die Republik den Republikanern! Das Reichsbanner Schwarz-Rot-Gold in Württemberg, in: Momente 4 (2002) S. 10-14; außerdem: Staatsanzeiger für Württemberg vom 26.11.1928 und vom 25.11.1929.

74 Württemberger Zeitung vom 23.10.1922 und vom 19.10.1925; Staatsanzeiger für Württemberg vom 26.11.1928 und vom 23.11.1931; Deutsches Volksblatt vom 21.11.1932; außerdem: HStA Stuttgart E 151/01 Bü 2923: Programm der Feier 1929.

75 Schwäbische Tagwacht vom 22.11.1919 und vom 1.11.1920; Württemberger Zeitung vom 24.10.1921, 23.10.1922 und vom 19.10.1925; Staatsanzeiger für Württemberg vom 26.11.1928, 24.11.1930 und vom 23.11.1931; Deutsches Volksblatt vom 21.11.1932; außerdem: HStA Stuttgart E 151/01 Bü 2923: Programm der Feier 1929. Zum Gesangverein ,Ehrenfeld“ allgemein vgl. auch: MüLLER, Waldfriedhof (wie Anm. 39) S. 360.

76 Vgl. Schiller (wie Anm. 5) S. 32. Die Gedenkreden bilden daher die Grundlage für die Analyse der Deutung der Kriegserinnerung.

77 Deutsches Volksblatt vom 22.11.1930. 
nur in den Jahren 1919, 1920 und 1924 sprachen weltliche Redner die Gedenkworte $^{78}$. Offensichtlich wurde dabei darauf geachtet, ein gewisses Gleichgewicht zwischen den Konfessionen herzustellen, denn evangelische und katholische Pfarrer wechselten sich in der Regel ab. Die Geistlichen traten dabei in ihrer Funktion als Kirchenmänner auf; nur in wenigen Fällen verwiesen sie in ihren Reden explizit auf eigene Fronterfahrungen und betonten so ihre Identität als Veteranen ${ }^{79}$. Die Redner kamen also im Allgemeinen nicht aus den Rängen der Veteranenverbände, mit einer einzigen Ausnahme im Jahr 1919, als der Reichsbund bei der von ihm auf den Weg gebrachten Gedenkfeier einen Redner stellte. Dessen Gedächtnisrede war aber nicht exklusiv, denn auch der Oberbürgermeister sowie Geistliche beider Konfessionen ergriffen noch zusätzlich das Wort ${ }^{80}$.

Die Tatsache, dass die Rednerfunktion in Württemberg nicht von Veteranen besetzt wurde, ist ein wesentlicher Befund: Die öffentliche Deutung des Kriegs wurde nicht ausdrücklich von jenen vollzogen, die an ihm teilgenommen hatten. Der Grund dafür liegt möglicherweise in der Struktur der Veteranenverbände. Da die

78 Das Quellenkorpus der weltlichen Redner setzt sich folgendermaßen zusammen: Die Reden von Oberbürgermeister Lautenschlager (Schwäbische Tagwacht vom 24.11.1919), von einem anonymen Vertreter des Reichsbunds der Kriegsbeschädigten (Schwäbische Tagwacht vom 24.11.1919) sowie von Bürgermeister Dollinger (Schwäbische Tagwacht vom 1.11.1920) werden in der Presse in Teilen paraphrasiert. Die Rede von Staatspräsident Wilhelm Bazille kann hingegen als vollständig überliefert betrachtet werden (Staatsanzeiger für Württemberg vom 30.7.1924). Bei den geistlichen Rednern scheinen die in der Presse überlieferten Reden von Divisionspfarrer Schwenk (Deutsches Volksblatt vom 4.8.1924), von Divisionspfarrer Mauch (Süddeutsche Zeitung vom 4.8.1924), von Oberkirchenrat Schaal (Staatsanzeiger für Württemberg vom 21.11.1927; Schwäbische Kronik des Schwäbischen Merkurs vom 21.11.1927), von Stadtpfarrer Spohn (Amtsblatt der Stadt Stuttgart vom 27.11.1928), von Stadtpfarrer Esenwein (Staatsanzeiger für Württemberg vom 26.11.1930) und von Stadtdekan Monsignore Rau (Amtsblatt der Stadt Stuttgart vom 24.11.1931) allesamt Anspruch auf Vollständigkeit erheben zu können. Nur teilweise und indirekt in den Zeitungsartikeln wiedergegeben wurden die Reden von Kaplan Vogt (Stuttgarter Neues Tagblatt vom 24.11.1919, Morgenausgabe), von Oberkirchenrat Traub (Stuttgarter Neues Tagblatt vom 24.11.1919, Morgenausgabe), von Stadtpfarrer Dr. Walter (manchmal auch „Walther" geschrieben; Schwäbische Tageszeitung vom 2.11.1920; Stuttgarter Neues Tagblatt vom 1.11.1920), von Stadtpfarrer Bentele (Württemberger Zeitung vom 24.10.1921), von Stadtpfarrer Fleck (Schwäbische Kronik des Schwäbischen Merkurs vom 25.10.1926), von Prälat Mayer-List (Staatsanzeiger für Württemberg vom 25.11.1929; Deutsches Volksblatt vom 25.11.1929; Schwäbische Tageszeitung vom 25./26.11.1929; Württemberger Zeitung vom 25.11.1929; Stuttgarter Neues Tagblatt vom 25.11.1929, Morgenausgabe) und von Stadtpfarrer Schauffler (Schwäbische Tageszeitung vom 21./22.11.1932; Deutsches Volksblatt vom 21.11.1932). Die nur partiell in den Quellen überlieferten Reden zur Einweihung des Gefallenendenkmals im Jahr 1923 (Stuttgarter Neues Tagblatt vom 16.7.1923, Abendausgabe) wurden ergänzt durch Angaben von Lurz (wie Anm. 5) S. 225.

79 Nur in den beiden Reden von Schaal (Staatsanzeiger für Württemberg vom 21.11.1927) und Spohn (Amtsblatt der Stadt Stuttgart vom 27.11.1928).

${ }^{80}$ Stuttgarter Neues Tagblatt vom 24.11.1919 (Morgenausgabe); Schwäbische Tagwacht vom 24.11.1919. 
Veteranenverbände in Deutschland ihren Ursprung in den politisch geprägten Milieustrukturen des Kaiserreichs hatten und außerdem in fast allen Fällen auch Nicht-Veteranen aufnahmen, waren sie ihrem Wesen nach überwiegend politisch ${ }^{81}$. Keiner der deutschen Veteranenverbände konnte für sich beanspruchen, den allgemeinen Willen der Veteranen zu vertreten ${ }^{82}$. Es gab in Deutschland auch keinen Dachverband, der einen Ausgleich zwischen den unterschiedlichen Verbänden hätte bewirken können. Ein solcher übergreifender sozialer Bezugsrahmen wäre aber für die Konstruktion eines gemeinsamen kollektiven Gedächtnisses der Veteranen wichtig gewesen ${ }^{83}$. Statt sich einander anzunähern, spalteten sich die divergierenden Erinnerungskonstruktionen der verschiedenen politischen Lager zunehmend voneinander $a b^{84}$.

Auch die politischen Vertreter der Stadt Stuttgart und der württembergischen Regierung übernahmen nur sehr selten die Rednerfunktion. Die Jahre 1919 und 1920, in denen der Stuttgarter Bürgermeister bei den städtischen Gedenkfeiern das Wort ergriff ${ }^{85}$ und das Jahr 1924, als Staatspräsident Wilhelm Bazille eine Rede vortrug $^{86}$, blieben Ausnahmen. Außerdem wurden selbst in diesen wenigen Fällen die Ansprachen der Politiker noch durch zusätzliche Reden von Geistlichen ergänzt ${ }^{87}$. Offensichtlich war das Konfliktpotenzial bei Reden von Politikern zu hoch, wie das erste der beiden folgenden Beispiele veranschaulicht. Dass aber auch die Übertragung der Rednerrolle an die Geistlichkeit kein Garant für eine friedliche Gedenkfeier war, wird im zweiten Beispiel deutlich werden.

\section{Politische Konflikte um die Gefallenengedenkfeiern}

In der untersuchten Zeitspanne fallen zwei Gedenkfeiern deutlich aus dem Rahmen: Unter der Staatspräsidentschaft von Wilhelm Bazille (Bürgerpartei) ${ }^{88}$ wurden die Feiern der Jahre 1924 und 1927 zum politischen Kampfplatz um die Deu-

${ }^{81}$ Vgl. hierzu: Ziemann, Milieukulturen (wie Anm. 72) S. 257; Diehl (wie Anm. 69) S. 137-139.

${ }^{82}$ Im Gegensatz zu Frankreich, wo die beiden größten Veteranenverbände der Zwischenkriegszeit sehr viel stärker auf Neutralität bedacht waren und außerdem ausschließlich Veteranen aufnahmen. Der Dachverband der,Confédération nationale des anciens combattants et victimes de la guerre vereinfachte außerdem die Kooperation der verschiedenen Verbände; vgl. Prost, Anciens Combattants (wie Anm. 37) S. 57; Antoine Prost, Les anciens combattants, in: L'Encyclopédie de la Grande Guerre 1914-1918, hg. von Stéphane Audoin-RouZeAu/Jean-Jacques Becker, Paris 2004, S. 1087-1097, hier S. 1091-1095.

83 Vgl. Halbwachs, Mémoire (wie Anm. 3) S. 53-58.

${ }^{84}$ Vgl. Ziemann, Milieukulturen (wie Anm. 72) S. 257.

${ }^{85}$ Stuttgarter Neues Tagblatt vom 24.11.1919 (Morgenausgabe) und vom 1.11.1920 (Abendausgabe); Schwäbische Tagwacht vom 24.11.1919 und vom 1.11.1920.

${ }^{86}$ Staatsanzeiger für Württemberg vom 30.7.1924.

87 Ebd.

88 Vgl. hierzu: Sauer (wie Anm. 9) S. 101-105; Hans Peter Müller, Die Bürgerpartei/ 
tung des Gefallenengedenktags in Württemberg. Im Jahr 1924 organisierte das württembergische Staatsministerium gemeinsam mit der Stadtverwaltung Stuttgart eine Gedenkfeier anlässlich des 10. Jahrestags der Kriegserklärung am 3. August $^{89}$. Bereits die Vorbereitungen der Feier stießen bei den Sozialdemokraten auf Kritik. Die Ankündigung des Staatsministeriums, dass „den Militärvereinen und dem Frontkämpferbund nach der Reichswehr“ der Vortritt zur Feier zu lassen sei $^{90}$, verurteilte die „Schwäbische Tagwacht“ als behördlichen Protektionismus dieser Verbände ${ }^{91}$. Die Kriegsopferorganisationen und deren Belange würden dagegen von der Regierung vernachlässigt. Man wolle daher auf die Teilnahme an dieser Veranstaltung verzichten, die nur „eine hohle Phrase, ein Kriegervereinsrummel, ohne inneren Gehalt und Mitempfinden“92 sei. Die Feierlichkeiten wurden am Abend des 2. August mit einem Weihekonzert im Hof der großen Infanteriekaserne in Stuttgart eingeleitet, bei dem die drei Militärkapellen des Standorts Stuttgart und der Stuttgarter Liederkranz mitwirkten ${ }^{93}$. Am folgenden Morgen, dem 3. August, fand dann um elf Uhr eine Gedenkfeier im Hof des Neuen Schlosses statt. Im Mittelpunkt des Programms standen die Reden von Staatspräsident Wilhelm Bazille, dem katholischen Divisionspfarrer Schwenk sowie dem evangelischen Divisionspfarrer Mauch. Sie wurden musikalisch umrahmt, namentlich von dem ,Niederländischen Dankgebet', dem ,Lied des guten Kameraden ' und schließlich von dem gemeinsam gesungenen ersten Vers des Deutschlandliedes ,Deutschland, Deutschland über alles ${ }^{\mathrm{9}}$.

Die Gedenkfeier löste in der linken Presse einen Sturm der Empörung aus: Stein des Anstoßes waren in erster Linie die Gedenkreden, da sie der Feier „einen parteipolitischen Anstrich“95 verliehen hätten. Das sozialdemokratische „Heilbronner Neckar-Echo“ betitelte seinen Artikel über die Gedenkfeier mit den Worten: „Bazille’s Dolchstoß - Nationalistischer Rummel - Geistliche mißbrauchen die Ge-

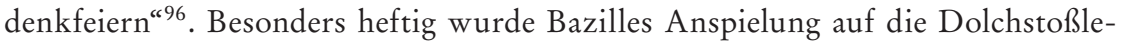
gende kritisiert: Er habe es vollbracht, „allen geschichtlichen Tatsachen zum Hohn

Deutschnationale Volkspartei (DNVP) in Württemberg 1918-1933, in: ZWLG 61 (2002) S. 375- 433, hier S. 378, 385.

${ }^{89}$ Staatsanzeiger für Württemberg vom 30.7.1924.

90 Ebd.

91 Schwäbische Tagwacht vom 30.7.1924.

92 Ebd.

${ }_{93}$ Ebd.

${ }^{94}$ Staatsanzeiger für Württemberg vom 30.7.1924. Der Vers ,Deutschland, Deutschland über alles' wurde in der Weimarer Zeit von der politischen Rechten vereinnahmt; vgl. Wolfgang Riвве, Flaggenstreit und Heiliger Hain. Bemerkungen zur nationalen Symbolik in der Weimarer Republik, in: Aus Theorie und Praxis der Geschichtswissenschaft 37 (1972)

S. 175-188, hier S. 180; Hattenhauer (wie Anm. 10) S. 53-57.

${ }_{95}$ Heilbronner Neckar-Echo vom 5.8.1924.

96 Ebd. 
aufs Neue, wenn auch in versteckten Wendungen, die Dolchstoßlegende hervorzuzerren und das deutsche Volk [...] der Verräterei zu bezichtigen“" ${ }^{\text {"97. }}$.

Damit bezog sich die „Schwäbische Tagwacht“ auf folgende Stellen von Bazilles Rede:

„[...] Das herrlichste Volksheer, das die Welt je gesehen hat, eilte zum Schutze des Vaterlandes an alle Grenzen. In dem vierjährigen gewaltigen Ringen zitterte die Welt vor den Schrecken der deutschen Waffen zu Land, zu Wasser und in der Luft, bis das Entsetzliche geschah, bis die uralte deutsche Zwietracht aus ihren Grüften stieg und dem stolzen Heere, wenn auch nicht die Kränze unsterblichen Ruhmes, so doch den Lorbeer des Sieges entwand. [...] In Fesseln geschlagen, aus tausend Wunden blutend, ein Gegenstand verachtungsvollen Hohnes - so warf die deutsche Zwietracht das deutsche Volk vor den Thron des Sieges und setzte auf ihn die Lüge im betrügerisch geraubten Mantel des Rechtes [...] “998

Die „Schwäbische Tagwacht“ versuchte die Dolchstoßlegende argumentativ zu entkräften: Zu einem Zeitpunkt, als die Unmöglichkeit des Sieges bereits deutlich gewesen sei, hätten die deutschen Heerführer ,jede Verständigungsmöglichkeit“ abgelehnt, den „Schwertfrieden“ erstrebt und dadurch Deutschlands Lage verschlimmert ${ }^{99}$. Die von Bazille beschworene Einheit der Deutschen während des Kriegs sei eine Fiktion, da sich die Bessergestellten besonders häufig vor dem Fronteinsatz gedrückt hätten ${ }^{100}$. Die hohen Militärs, so die weiteren Ausführungen, hätten die einfachen Soldaten oft schlecht behandelt. Schließlich habe der Wuchergeist der besitzenden Kreise viele Familien von Kriegsteilnehmern in die Armut gestürzt ${ }^{101}$. Diese Argumentationskette folgte offenbar dem Deutungsschema ,Klassenkampf ' und knüpfte damit an interpretative Traditionen der sozialdemokratischen Arbeiterkultur des Kaiserreichs an ${ }^{102}$. Die „Schwäbische Tagwacht“ äußerte außerdem die Befürchtung, die Nationalisten in Frankreich würden Bazilles Rede als Beweis für die Existenz eines deutschen Militarismus anführen. Bazille hätte ihnen Argumente für ihr Vorgehen gegen den französischen Ministerpräsidenten Edouard Herriot geliefert, der sich um Entspannung und Annäherung in der französischen Deutschlandpolitik bemühte ${ }^{103}$. Dadurch würde Bazilles Rede letztendlich „zum Dolchstoß gegen das eigene Volk“104. Die Reden der beiden Divisionspfarrer wurden von der sozialdemokratischen Presse ebenfalls scharf angegriffen. Der evangelische Divisionspfarrer Mauch hatte seiner Rede folgende Verse vorangestellt:

${ }^{97}$ Schwäbische Tagwacht vom 4.8.1924.

98 Staatsanzeiger für Württemberg vom 4.8.1924.

99 Schwäbische Tagwacht vom 4.8.1924.

100 Ebd.

101 Ebd.

102 Vgl. Ziemann, Milieukulturen (wie Anm. 72) S. 255-256.

103 Vgl. etwa Eberhard Kolb/Dirk Schumann, Die Weimarer Republik, München ${ }^{8} 2013$, S. 59-61.

104 Schwäbische Tagwacht vom 4.8.1924; Heilbronner Neckar-Echo vom 5.8.1924. 
„Ehret die Toten im Zeichen der Farben,

für welche sie starben:

Schwarz-Weiß-Rot!

Ehret die Toten und hört, was sie sagen,

wie tief sie beklagen

Deutschlands Not! “105

Auch der katholische Divisionspfarrer Schwenk hatte die Farben Schwarz, Weiß und Rot ins Zentrum seiner Ausführungen gestellt:

„Heute [...] versammelt sich ganz Deutschland [...] und greift instinktiv mit einer gewissen Andacht nach dem sichtbaren Wahrzeichen und Erkennungszeichen deutscher Art und Ehre, der deutschen Kriegsfahne. [...] Schwarz - die erste Ehrenbezeichnung und Huldigung für die toten Söhne des Vaterlandes. [...] Weiß ist das Symbol des Lichtglanzes und der Lichtempfindung. [...] Das freiwillige Sterben fürs Vaterland, der rückhaltlose und rücksichtslose Einsatz des Lebens für das Volk ist kein dunkles Verhängnis, dem man sich ohnmächtig fügt $[\ldots]$. ${ }^{106}$

Die sozialdemokratischen Blätter kritisierten, beide Redner hätten die Farben des Kaiserreichs Schwarz, Weiß und Rot sowie den Opfertod für das Vaterland in einem solchen Ausmaß verherrlicht, dass ihre Bedenken, den Geistlichen die Reden $\mathrm{zu}$ übertragen, durchaus angebracht gewesen seien ${ }^{107}$. Mindestens genauso ablehnend wie die sozialdemokratische Presse reagierte die kommunistische „Süddeutsche Arbeiterzeitung“. Sie veröffentlichte die Karikatur eines beleibten Pfarrers, der auf einem Hügel, allem Anschein nach aufgetürmt aus Toten und Verletzten, steht und predigt (Abb.4) ${ }^{108}$. Zu seinen Füßen sind Kriegsverletzte im Stil von Otto Dix zu sehen, während offensichtlich hohe Militärs um ihn herum strammstehen. Der Titel der Karikatur lautet: „Die Pfaffen sind zu allen Dingen nütz. Heute, wie 1914!“ Unter der Karikatur stehen die Worte „Im Namen Gottes und des - Militarismus ...“. Die Botschaft der Karikatur war deutlich: Die kommunistische Partei kritisierte die Kirche, ihre Rolle im Weltkrieg und ihre Sympathien für den monarchistischen Militarismus. Der „Beobachter“, das Presseorgan der DDP, stimmte in die negative Bewertung der Feier ein ${ }^{109}$. Er rügte ebenfalls Bazilles Anspielung auf die Dolchstoßlegende und bemühte sich, die tatsächliche Situation richtig zu stellen. Parteipolitische Behauptungen, so seine Forderung, seien bei solcherlei Feiern in Zukunft zu unterlassen. Die Presseorgane der Bürgerpartei

105 Süddeutsche Zeitung vom 4.8.1924.

106 Deutsches Volksblatt vom 4.8.1924.

107 Schwäbische Tagwacht vom 4.8.1924; Heilbronner Neckar-Echo vom 5.8.1924. Zur symbolischen Bedeutung der Farben vgl. Hattenhauer (wie Anm. 10) S. 22-29.

108 Zur Karikatur im Folgenden siehe Abb. 4: Karikatur zum Gefallenengedenktag in der Süddeutschen Arbeiterzeitung vom 5.8.1924. Offensichtlich wurden hier die Reden vom Karikaturisten den jeweiligen Rednern falsch zugeordnet.

109 Der Beobachter vom 9.8.1924. 
und des Bauernbundes bewerteten die Feier hingegen durchweg positiv ${ }^{110}$. Auch die Zeitung der Zentrumspartei, das „Deutsche Volksblatt“, ließ keinerlei Kritik an der Gefallenengedenkfeier verlauten ${ }^{111}$.

Im Herbst 1927 wurde der Gedenktag in Württemberg erneut zum Auslöser hitziger Auseinandersetzungen. In diesem Jahr organisierten die Staatsregierung und die Stadtverwaltung zum ersten Mal eine gemeinsame Feier am nunmehr offiziellen württembergischen Gefallenengedenktag ${ }^{112}$. Zur Vorbereitung der Veranstaltung fand am 9. November im Staatsministerium eine Besprechung mit Vertretern der verschiedenen Verbände statt, die sich alle zur Teilnahme an der Feier bereit erklärten ${ }^{113}$. Am Tag vor der Veranstaltung nahm das Reichsbanner, Ortsverband Stuttgart, seine Zusage zur Teilnahme wieder zurück ${ }^{114}$. Sein Vorsitzender, Kurt Schumacher, begründete diesen Schritt folgendermaßen: Es erscheine dem Reichsbanner „untragbar [...], die Bünde und Verbände zu den eigentlichen Trägern der Veranstaltung zu machen, zumal in ihrem geschlossenen und uniformierten Auftreten mit ihren Fahnen und Emblemen“115. Dadurch erscheine „der Ortsgruppe der Geist des Friedens gefährdet, von dem ihrer Ansicht nach jede Ehrung der Gefallenen beseelt sein“"116 müsse. Diese Absage beschränkte sich allerdings nur auf einen Teil des Verbandes, denn laut Mitteilung der Geschäftsstelle der DDP fühlten sich ihre Mitglieder des Reichsbanners nicht an diesen Beschluss gebunden ${ }^{117}$. Die Gedenkfeier fand dann am Vorabend des Totensonntags, am 19. November, im Hof des Neuen Schlosses in Stuttgart statt ${ }^{118}$. Sie wurde von einem Fackelzug eingeleitet, der von der Rotebühlkaserne durch die Königsstraße zum Schloßhof führte. Oberkirchenrat Schaal trug die Gedenkrede vor, an musikalischer Begleitung ist vor allem der Vers ,Deutschland, Deutschland über alles ${ }^{119}$ erwähnenswert. Die Gedenkzeremonie verlief planmäßig und ohne die Anwesenheit des Reichsbanners ${ }^{120}$.

110 Süddeutsche Zeitung vom 4.8.1924; Schwäbische Tageszeitung vom 5.8.1924.

111 Deutsches Volksblatt vom 4.8.1924.

112 Schwäbische Tagwacht vom 19.11.1927.

113 Ebd.

114 Schreiben von Kurt Schumacher als Vorsitzender der Ortsgruppe Stuttgart des „Reichsbanners Schwarz-Rot-Gold“ an das Württembergische Staatsministerium vom 18.11.1927, zitiert in: Wilfried BraUnN, Kurt Schumacher und die Gefallenengedenkfeier 1927 in Stuttgart, in: ZWLG 50 (1991) S. 419-423, hier S. 420-421.

115 Ebd.

116 Ebd.

117 Ebd., außerdem: Württemberger Zeitung vom 19.11.1927; Stuttgarter Neues Tagblatt vom 19.11.1927 (Morgenausgabe).

118 Vgl. Braunn (wie Anm. 114) S. 420; außerdem: Staatsanzeiger für Württemberg vom 14.11.1927.

119 HStA Stuttgart E 151/01 Bü 2923: Vortragsfolge der Lieder 1927.

120 Ebd., außerdem: Württemberger Zeitung vom 19.11.1927; Stuttgarter Neues Tagblatt vom 19.11.1927 (Morgenausgabe). 


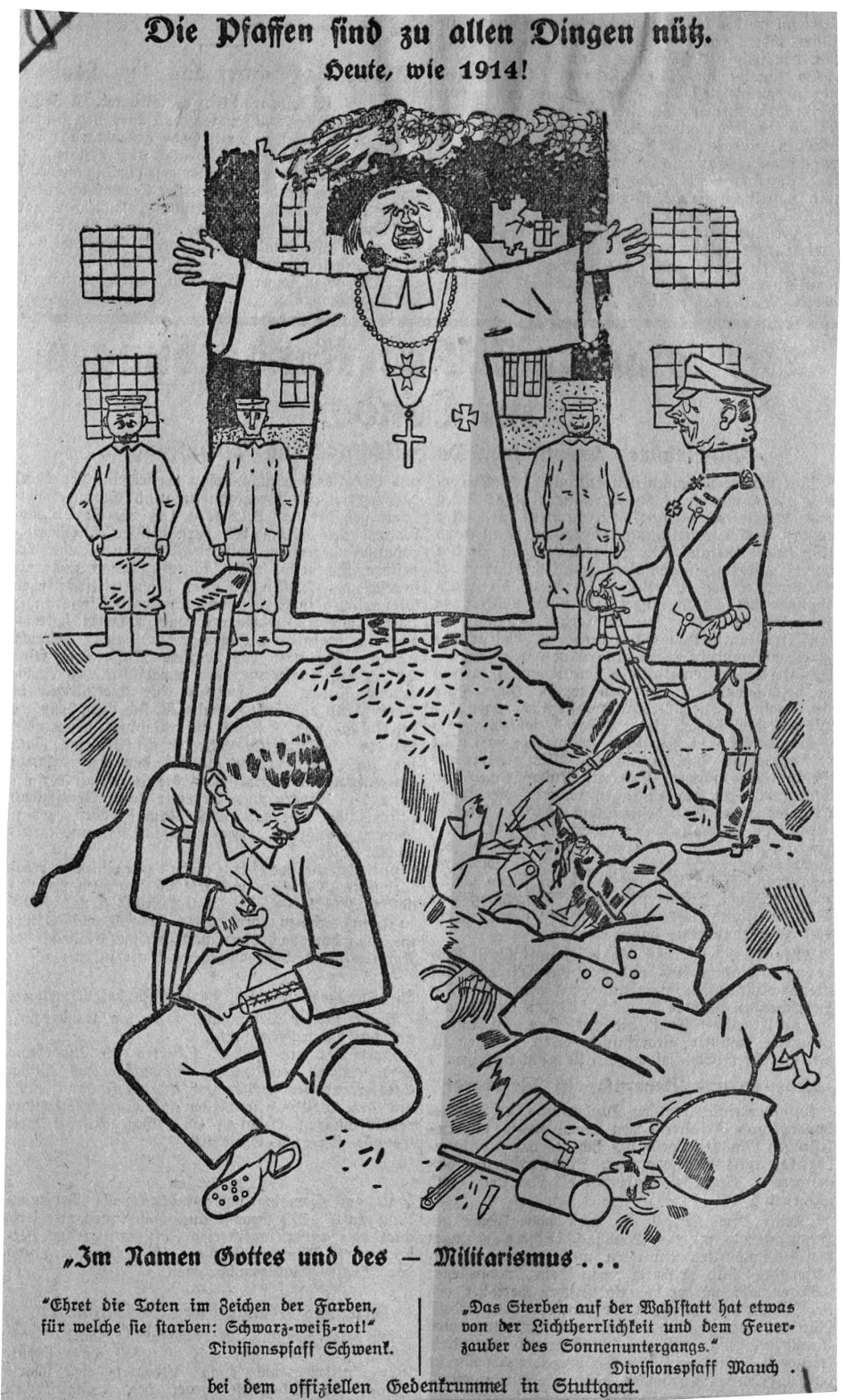

Abb. 4: Karikatur zum Gefallenengedenktag am 4. August 1924 in der "Süddeutschen Arbeiterzeitung" vom 5. August 1924 (Vorlage: HStA Stuttgart E 130 b Bü 3846). 
Nach der Feier übte die sozialistische Presse harsche Kritik an ihrem Verlauf. Die „Schwäbische Tagwacht“ kommentierte die Rede zum Beispiel mit folgenden Worten: „Wir verstehen es ist schwer, sehr schwer, eine Gedächtnisrede auf die Kriegsopfer zu halten. Die Antworten über das ,Warum?‘ und ,Wofür?‘ sind im deutschen Volk sehr verschieden, und in den Völkern bricht sich überall langsam eine Wandlung in der Wertung des Krieges Bahn [...]. “121 Die Gedenkrede, so die „Schwäbische Tagwacht“, spiegle die monarchistische Prägung von Kirchenrat Schaal wider, am deutlichsten in der Wendung: „Wenn die einen und nicht die schlechtesten von uns an der Vergangenheit hängen [...] sich dagegen wehren, wenn die Vergangenheit schlecht gemacht wird [...]. “122 Außerdem zeige sich die Verherrlichung des Kaiserreichs in der Tatsache, dass „von Reichswehr- und Schupokapelle die reaktionärsten und klirrendsten Preußenmärsche der Monarchie geschmettert worden“ seien ${ }^{123}$. Der Fackelzug sei „alles andere als imponierend“ gewesen und überwiegend von jungen Leuten gebildet worden, „die bei Kriegsende noch nicht konfirmiert“ gewesen seien ${ }^{124}$. Damit sprach die „Schwäbische Tagwacht“ den Teilnehmern des Fackelzuges indirekt die Legitimation zur Deutung der Kriegserinnerung ab. Die rechtsgerichteten Verbände hätten sich den Gefallenen gegenüber respektlos verhalten, was sich darin geäußert habe, dass „beim Abmarsch im Schloßhof in den Reihen des Stahlhelms geraucht“ worden und „aus den Gruppen eines Kriegervereins ein dröhnendes Gelächter erscholl[en] “125 sei. Der Autor des Artikels befürwortete die Entscheidung des Reichsbanners, der Feier fernzubleiben, denn es sei unzumutbar, „mit Fridericusmarsch, unter Fahnen, unter denen bis heute der Revanchekrieg gepredigt wird, und im Geiste des alten Systems der Gefallenen des Krieges zu gedenken“126. Die kommunistische Presse schloss sich dieser Kritik an. Die „Süddeutsche Arbeiterzeitung“ schrieb:

„Aber die Regierung Bazille gedenkt nicht der Gesamtheit der Gefallenen des Weltkriegs, nein, in ihrer partikularistischen Einstellung betotenfeiert sie nur ,ihre' Landeskinder. Sie erschrickt wohl vor der Breite des Blutstroms, der in dieser Nacht des Gedenkens aus den noch feuchten Massengräbern Europas hervorquillt. [...] Die Etappenorden wackelten über den inzwischen zum Teil recht umfänglich gewordenen Bäuchen, die durch den Stechschritt

121 Schwäbische Tagwacht vom 21.11.1927.

122 Ebd. Der Abschnitt, auf den hier Bezug genommen wurde, lautete dem Schwäbischen Merkur zufolge: „Wir reden von Aufstieg, aber wir kommen nicht weiter, solange die einen die Vergangenheit, an der so viele - und nicht die schlechtesten unter uns - hängen, mit allen Mitteln und bei jeder Gelegenheit klein machen. Wir kommen nicht weiter, solange andere die Gegenwart, so wie sie geworden ist und wie wir sie sehen müssen, mit allen Mitteln und bei jeder Gelegenheit klein machen. Wir kommen nie zusammen, solange immer wieder jenes Bibelwort auch im Blick auf unser Volksleben leider wahr bleibt: ,Ein jeglicher sah auf seinen Weg“"; Schwäbische Kronik des Schwäbischen Merkurs vom 21.11.1927.

123 Schwäbische Tagwacht vom 21.11.1927.

124 Ebd.

125 Ebd.

126 Ebd. 
erschüttert wurden. [...] Man fühlte die Künstlichkeit, mit der das Ganze arrangiert war. Man spürte die Hände der Regisseure. Das war eben keine Bewegung, spontan herausgewachsen aus der Masse, aus den erschütternden Leidtragenden vierjährigen Völkerwahnsinns, nein, das war weiter nichts, als kühl und überlegt organisierte Trauer. Trauer auf Eintrittskarten sozusagen, Trauer für die Privilegierten. [...] Eine Veranstaltung, die, recht verstanden, ihrem innersten Wesen nach nichts anderes bedeutet, als Werbung und Auftakt zu neuem blutwütigem Beginnen." ${ }^{127}$

Außer bei SPD und KPD scheint die Gedenkfeier allerdings nicht auf Kritik gestoßen zu sein, auch nicht bei der DDP ${ }^{128}$. Das „Deutsche Volksblatt“ missbilligte sogar das Verhalten des Reichsbanners, da es den grundlegenden Gedanken der Einigkeit zerstört und die Überparteilichkeit der Feier verletzt habe ${ }^{129}$. Die Regierung betonte in einem Briefwechsel mit dem Reichsbanner den „weihevolle[n] Verlauf der Feier"130, während Kurt Schumacher hingegen die Auswahl der Märsche und „auch gewisse Wendungen der Gedenkrede“ beanstandete ${ }^{131}$. Die Beispiele der Jahre 1924 und 1927 zeigen, wie hoch die politische Sprengkraft der Erinnerungsdeutung in der Weimarer Zeit war. Diese Jahre blieben allerdings offenbar ein Ergebnis der Bemühungen um einen friedvollen Ablauf der Feiern Ausnahmen.

Die Tatsache, dass die Erinnerung an den Ersten Weltkrieg bei den öffentlichen Gedenkfeiern in Württemberg in der großen Mehrheit der Fälle nicht politisch ausgedeutet wurde, ist bemerkenswert. Während nach dem Krieg von 1870/71 der Kult um die Gefallenen mit der Idee der Reichseinheit verknüpft wurde, blieb der Platz einer allgemeinen öffentlichen Sinnstiftung nach dem Ersten Weltkrieg vakant $^{132}$. Dass zum Beispiel Stadtpfarrer Fleck in seiner Rede des Jahres 1926 eine gedankliche Brücke zwischen dem Krieg von 1870/71 und dem Ersten Weltkrieg schlug, verweist offenbar auf einen Mangel an neuen überzeugenden Deutungsmu$\operatorname{stern}^{133}$.

127 Süddeutsche Arbeiterzeitung vom 21.11.1927.

128 In der Württemberger Zeitung vom 21.11.1927 wird der Verlauf der Feier als „eindrucksvoll" beschrieben.

129 Vgl. Braunn (wie Anm. 114) S. 420; außerdem: Deutsches Volksblatt vom 21.11.1927.

130 Antwort des Staatsministeriums an das Reichsbanner (Ortsgruppe Stuttgart) vom 22.11.1927, zitiert in: Braunn (wie Anm.114) S. 421.

131 Kurt Schumacher für die Ortsgruppe an das Staatsministerium vom 28.11.1927, zitiert in: Braunn (wie Anm. 114) S. 422-423.

${ }^{132}$ Vgl. Siegfried Seeger, Wandlungen in der Einstellung zum Krieg. Dargestellt an den westfälischen Ehrenmalen für die Kriegstoten, Münster 1962, S. 30-31, 95-97. Im Unterschied zu Frankreich, wo sich dank der gefestigten politischen Kultur der Dritten Republik die mehrheitsfähige Interpretation einer republikfreundlichen Kriegserinnerung etablierte; vgl. hierzu: Antoine Prost, Les monuments aux morts, in: Les lieux de mémoire, Bd.1, hg. von Pierre Nora, Paris ${ }^{2} 1997$, S. 199-223, hier S. 211; Bessel (wie Anm. 4) S. 139.

133 Fleck: „Groß und zukunftsreich hatte er [d.h. der Erste Weltkrieg] eingesetzt und schien $\mathrm{zu}$ den besten Hoffnungen $\mathrm{zu}$ berechtigen und schien $\mathrm{zu}$ vollenden, was der deutsch-französische Krieg vor 45 Jahren begonnen, uns zur Innigkeit und Einigkeit zusam- 
Das Fehlen eines Konsenses in Bezug auf die Kriegsdeutung wurde in Deutschland sehr wahrscheinlich durch die Abwesenheit eines nationalen Bezugsrahmens sowohl bedingt als auch verstärkt. Es existierte weder ein konkretes Ereignis in Form eines reichsweiten Gedenktags ${ }^{134}$ noch ein Erinnerungsort in Gestalt eines nationalen Gefallenendenkmals, mittels derer sich ein nationales kollektives Gedächtnis hätte bilden können ${ }^{135}$. Ein solches nationales Denkmal war zwar seit 1924 in Planung, wurde aber nicht verwirklicht ${ }^{136}$. Auch in der Berichterstattung der analysierten regionalen Presse spiegelt sich diese Abwesenheit einer nationalen Bezugnahme: Die württembergischen Zeitungen berichteten kaum von Gedenkfeiern in Berlin oder in anderen deutschen Ländern und unterließen es somit ebenfalls, einen nationalen Bezugsrahmen $\mathrm{zu}$ schaffen. Die föderative Tradition Deutschlands war sicherlich in einem hohen Maße für diese Entwicklungen mitverantwortlich. Es scheint, dass kollektive Deutungsmuster der Erinnerung an den Ersten Weltkrieg in Deutschland außerhalb der politischen Milieustrukturen wohl überhaupt nur auf regionaler Ebene gefasst werden können.

\section{Die öffentliche Deutung der Kriegserfahrung in Stuttgart}

Als Erstes gilt es folgende grundlegende Aussage festzuhalten: In Württemberg war das öffentliche Erinnern an den Ersten Weltkrieg in allererster Linie ein Gedenken an die Toten, das mit dem Gefühl der Trauer einherging ${ }^{137}$. Das zeigt sich bereits in der Wahl des Waldfriedhofs als Erinnerungsort und des Totensonntags

menzuschließen, denn es hatte sich als Notwendigkeit erwiesen, daß Nord und Süd des deutschen Volkes für immer zusammengehören“; Schwäbische Kronik des Schwäbischen Merkurs vom 25.10.1926.

134 Vgl. Hattenhauer (wie Anm. 10) S. 128-145.

135 Vgl. Halbwachs, Topographie (wie Anm.3) S. 9. In Frankreich entstand z.B. relativ rasch nach Ende des Krieges ein stabiler nationaler Bezugsrahmen für das Gedenken an den Ersten Weltkrieg, zeitlich fixiert v. a. durch den Tag des Waffenstillstands am 11. November und räumlich durch das nationale Gefallenendenkmal, das ,Grab des Unbekannten Soldaten in Paris; vgl. Mosse, Gefallen (wie Anm. 4) S. 117-120.

136 Stattdessen wurden mehrere größere Denkmäler errichtet, denen es aber allen an reichsweiter Ausstrahlungskraft fehlte; vgl. hierzu: Mosse, Gefallen (wie Anm.4) S.117120; Benjamin Ziemann, Die deutsche Nation und ihr zentraler Erinnerungsort. Das ,Nationaldenkmal für die Gefallenen im Weltkriege' und die Idee des ,Unbekannten Soldaten 1914-1935, in: Krieg und Erinnerung. Fallstudien zum 19. und 20. Jahrhundert, hg. von Helmut Berding/Klaus Heller/Winfried Speitkamp, Göttingen 2000, S. 67-91, hier S. 67-69. Außerdem für Frankreich: Volker AckermanN, „Ceux qui sont pieusement morts pour la France ..... Die Identität des Unbekannten Soldaten, in: Der politische Totenkult. Kriegerdenkmäler in der Moderne, hg. von Reinhart Koselleck/Michael Jeismann, München 1994, S. 281-314; Koselleck, Totenkult (wie Anm. 51) S. 16.

137 Die Trauer drückt sich z.B. in den gespielten Trauermärschen aus: HStA Stuttgart E 151/01 Bü 2923: Vortragsfolge der Jahre 1927-1929 und 1932; außerdem für das Jahr 1931: Amtsblatt der Stadt Stuttgart vom 21.11.1931. Auch die Verwendung von traditioneller Grab- 
als Gedenktag. Der Kreis der Toten, an den erinnert wurde, ging dabei weit über die Zahl der auf dem Waldfriedhof bestatteten Soldaten hinaus ${ }^{138}$ : Der Katafalk, der bei den Feiern ab 1928 aufgestellt wurde, war ein symbolisches Grab aller, auch der anonym gefallenen, Soldaten ${ }^{139}$. Der Prozess des Sterbens an sich wurde in den Gedenkreden nur selten thematisiert. Pfarrer Schauffler erinnerte zum Beispiel im Jahr 1932 an die Gefallenen, „die ein schneller Tod auf dem Schlachtfeld dahinraffte, oder ein langsames, qualvolles Sterben im Lazarett“ ${ }^{\star 140}$. Nur ein einziges Mal wurde das Sterben ausdrücklich verherrlicht, und zwar von Divisionspfarrer Schwenk in seiner viel kritisierten Rede des Jahres 1924: „Das Sterben auf der Walstatt hat etwas von der Lichtherrlichkeit und dem Feuerzauber des Sonnenuntergangs. “141 Häufig hingegen war die diskursive Verknüpfung des Soldatentodes mit dem Mythos der ,Frontkameradschaft ${ }^{{ }^{142}}$, zum Beispiel von Oberkirchenrat Schaal mit den folgenden Worten: „Kameradenhände legten sie zur Ruhe, Kameradenaugen sahen ihnen nochmals in das stille Gesicht, Kameradenmund sprach leise zu ihnen: ,Bleib du im ewigen Leben mein guter Kamerad.“"143 Oberkirchenrat Schaal griff hier auf den Text des, Lieds des guten Kameraden' zurück, den er zwar variierte, dessen Grundaussage aber erhalten blieb: Das Lied beschreibt die treue Kameradschaft zweier Soldaten, von denen einer, von einer Kugel tödlich getroffen, stirbt. Indem der Tod des Kameraden stark individualisiert dargestellt wird, beschönigt das Lied indirekt die Kriegswirklichkeit des anonymen Massentodes ${ }^{144}$.

Die öffentlichen Erinnerungsfeiern dienten nicht der Kriegsverherrlichung; der Krieg wurde in der Regel als etwas Negatives dargestellt. Die Redner verwendeten zum Beispiel die Ausdrücke „ungeheures“ oder „gewaltiges Sterben“145 und be-

symbolik, wie z.B. den Schalen mit brennendem Feuer, verweist darauf, dass Trauer ein Charakteristikum der Feiern war; vgl. Lurz (wie Anm. 5) S. 248-249.

138 Württemberg hatte insgesamt fast 73.000 Tote zu beklagen; vgl. Thomas Schnabel, Geschichte von Baden und Württemberg 1900-1952, Stuttgart 2000, S. 79-80. Von den insgesamt circa 8.500 Stuttgarter Gefallenen fanden nur wenige in ihrem Heimatort die letzte Ruhe; vgl. Müller, Waldfriedhof (wie Anm. 39) S. 359.

139 Die zeitgenössische Tagespublizistik spricht von einem „Katafalk“ (Staatsanzeiger für Württemberg vom 26.11.1928), einer „Tumba“ (Württemberger Zeitung vom 25.11.1929), einem „Soldatengrab“ (Deutsches Volksblatt vom 21.11.1932), einem „Grab des gefallenen Soldaten“ (Schwäbische Tagwacht vom 24.11.1930) oder von einem „Grab des unbekannten Soldaten“ (Deutsches Volksblatt vom 25.11.1929; Schwäbische Tageszeitung vom 21./22.11.1932). Vgl. auch: Mosse, Gefallen (wie Anm.4) S. 116-124; Koselleck, Totenkult (wie Anm. 51) S. 15.

140 Deutsches Volksblatt vom 21.11.1932.

141 Deutsches Volksblatt vom 4.8.1924.

142 Z.B. bei Mauch (Süddeutsche Zeitung vom 4.8.1924), Esenwein (Staatsanzeiger für Württemberg vom 26.11.1930) und Rau (Amtsblatt der Stadt Stuttgart vom 24.11.1931).

143 Staatsanzeiger für Württemberg vom 21.11.1927.

144 Vgl. Latzel (wie Anm. 2) S. 65.

145 Rau (Amtsblatt der Stadt Stuttgart vom 24.11.1931). 
zeichneten den Krieg als „Grausamkeit“146, „Schrecken“147 oder „Greuel“148. Der Kriegsschauplatz wurde als „Hölle von Verdun“ oder als „Somme-Wüste“149 beschrieben. Stadtpfarrer Esenwein plädierte in eindrücklichen Worten dafür, den Krieg im Nachhinein nicht zu idealisieren:

„Und diese Frontsoldaten - sie wollten und wollen diesen Krieg, den sie durchkämpft haben, von den kommenden Geschlechtern nicht im Lichte verklärender Romantik gesehen wissen. Wir sollen ihn vielmehr sehen in seiner grandiosen Wirklichkeit, wir sollen ihn sehen in seiner alles Menschenbegreifen übersteigenden ungeheuren Wucht, wir sollen ihn sehen in seinem jede menschliche Vorstellung hinter sich lassenden furchtbaren Grauen. Das sagen uns die Gräber der Millionen Gefallener. “150

Ein solch expliziter Verweis auf die Schrecken des Kriegs blieb allerdings ein Einzelfall. Euphemistische Wendungen waren aber ebenso selten und beschränkten sich weitgehend auf die nationalistischen Reden der Jahre 1924 und 1927, in denen der Krieg zum Beispiel als „heißer Kampf“151 oder „großes Ringen“"152 bezeichnet wurde. Der Stahlhelm, die gekreuzten Bajonette und die Lanzen, mit denen der Platz der Gedenkfeiern ab 1928 geschmückt wurde, versinnbildlichten sicherlich den Krieg. Im Kontext der württembergischen Erinnerungsfeiern gibt es aber keinen Anlass, diese Kriegsobjekte als allegorische Bedeutung einer latenten Aufforderung zur Fortsetzung des Kriegs zu deuten, wie dies etwa Meinhold Lurz in seiner Untersuchung der Weimarer Kriegerdenkmäler vorschlägt ${ }^{153}$. Die Fronterfahrung der Soldaten wurde nur selten eingehender thematisiert, zum Beispiel wenn von „den dunklen Gräben und Unterständen“ und von Nächten „voll höllischen Lärms und drohender Gefahr“154 gesprochen wurde. Die Formulierung, die Soldaten hätten „draußen Unsagbares erduldet“"155, verweist auf die Schwierigkeit, die Kriegserfahrung in Worte zu fassen. Tod und Sterben der Soldaten, Leid und Schrecken der Fronterfahrung wurden zwar nicht verherrlicht, sie wurden aber häufig nur umschrieben oder ganz ausgeblendet.

Aufschlussreich ist, dass bei den württembergischen Gedenkfeiern pazifistische Überzeugungen kaum eine Rolle spielten ${ }^{156}$. Die als negativ bewertete Kriegser-

146 Spohn (Amtsblatt der Stadt Stuttgart vom 27.11.1928).

147 Schaal (Staatsanzeiger für Württemberg vom 21.11.1927); Esenwein (Staatsanzeiger für Württemberg vom 26.11.1930).

148 Schaal (Staatsanzeiger für Württemberg vom 21.11.1927).

149 Ebd.

150 Esenwein (Staatsanzeiger für Württemberg vom 26.11.1930).

151 Schwenk (Deutsches Volksblatt vom 4.8.1924).

152 Schaal (Staatsanzeiger für Württemberg vom 21.11.1927).

153 Lurz (wie Anm. 5) S. 246-247.

154 Spohn (Amtsblatt der Stadt Stuttgart vom 27.11.1928).

155 Esenwein (Staatsanzeiger für Württemberg vom 26.11.1930).

156 Im Gegensatz zu Frankreich, wo die Gedenkfeiern am 11. November überwiegend pazifistisch geprägt waren; vgl.: Prost, Les anciens (wie Anm. 82) S. 1095-1096; Antoine Prost, Pacifismes de l'entre-deux-guerres, in: L’Encyclopédie de la Grande Guerre 1914- 
fahrung führte offenbar nicht zu einer generellen Ablehnung des Kriegs. Wenn das Konzept des Friedens überhaupt erwähnt wurde, dann zumeist in Bezug auf den als ungerecht empfundenen Versailler Frieden ${ }^{157}$. Stadtpfarrer Esenwein thematisierte den Frieden zum Beispiel mit folgenden Worten:

„Rings um das abgerüstete Deutschland starren die Nationen mehr als je in Waffen, in Waffen, die immer vernichtender, immer unritterlicher, immer unmenschlicher werden. Was soll daraus entstehen? Wir können doch wahrlich nicht glauben, dies sei der Sinn der Todesopfer all der Millionen, dass die Völker Europas in einem neuen, noch viel grauenvolleren Ringen sich selbst zerfleischen und vernichten, von Wahnwitz betört. Hinüber und herüber haben in letzter Zeit alte Frontsoldaten an Gräbern von Gefallenen früher feindlicher Nationen Kränze niedergelegt. Ist das nur eine schöne Geste internationaler Höflichkeit? Oder soll es, ja muß es nicht vielmehr ein Zeichen des Willens zu echtem Frieden sein? Zu einem Frieden, der auf der Überzeugung beruht, dass wahre tiefe Vaterlandsliebe das Vaterland der andern nicht verachtet und nicht vergewaltigen will, vielmehr für jede Nation Recht und Freiheit und Achtung vor ihrer Eigenart und ihrem Daseinswert fordert. Das verlangen wir, wie von uns selbst, so auch für uns von den anderen Völkern; das fordern wir an den Gräbern unserer Tapferen. “158

Statt bei den negativen Aspekten des Kriegs zu verweilen, bemühten sich die Redner, ihm etwas Positives abzugewinnen: Im Zentrum der Gedenkreden standen daher Sinnstiftungsversuche, die auf der Idee des Opfertodes der Gefallenen gründeten. Die häufigste Aussage der württembergischen Reden war, die Gefal-

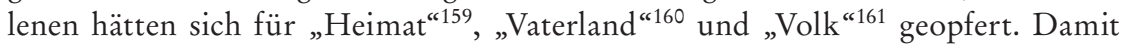
rekurrierten die Redner auf drei Begriffe, die im Zentrum des politischen Sprachhaushalts der Weimarer Republik standen und parteiübergreifend verwendet wur$\operatorname{den}^{162}$. Reinhart Koselleck zufolge sind sie eng miteinander verbunden und verweisen auf eine „sittlich-religiöse, politisch-soziale und geschichtliche Letztinstanz,

1918, hg. von Stéphane Audoin-Rouzeau/Jean-Jacques Becker, Paris 2004, S.1215-1226, hier S. 1217-1218.

157 Nur in drei Reden wurde die Frage des Friedens thematisiert: Mayer-List (Stuttgarter Neues Tagblatt vom 25.11.1929, Morgenausgabe); Esenwein (Staatsanzeiger für Württemberg vom 26.11.1930); Rau (Amtsblatt der Stadt Stuttgart vom 24.11.1931).

${ }^{158}$ Esenwein (Staatsanzeiger für Württemberg vom 26.11.1930).

159 Traub (Stuttgarter Neues Tagblatt vom 24.11.1919, Morgenausgabe); Fleck (Schwäbische Kronik des Schwäbischen Merkurs vom 25.10.1926); Mayer-List (Deutsches Volksblatt vom 25.11.1929); Esenwein (Staatsanzeiger für Württemberg vom 26.11.1930); Rau (Amtsblatt der Stadt Stuttgart vom 24.11.1931).

160 Vogt (Stuttgarter Neues Tagblatt vom 24.11.1919, Morgenausgabe); Schwenk (Deutsches Volksblatt vom 4.8.1924); Fleck (Schwäbische Kronik des Schwäbischen Merkurs vom 25.10.1926); Mayer-List (Deutsches Volksblatt vom 25.11.1929); Esenwein (Staatsanzeiger für Württemberg vom 26.11.1930); Rau (Amtsblatt der Stadt Stuttgart vom 24.11.1931).

161 Schwenk (Deutsches Volksblatt vom 4.8.1924); Schaal (Staatsanzeiger für Württemberg vom 21.11.1927); Mayer-List (Deutsches Volksblatt vom 25.11.1929); Esenwein (Staatsanzeiger für Württemberg vom 26.11.1930); Schauffler (Deutsches Volksblatt vom 21.11.1932).

${ }^{162}$ Vgl. Reinhart Koselleck, Volk, Nation, Nationalismus, Masse, in: Geschichtliche 
die nicht überboten werden kann“163. Die patriotische Opfersemantik der Reden wurde durch symbolische Objekte verstärkt, zum Beispiel die Schalen mit brennendem Feuer ${ }^{164}$. Nur selten wurde diese Trias in den Gedenkreden noch ergänzt, wenn zum Beispiel die beiden Divisionspfarrer Mauch und Schwenk in ihren umstrittenen Reden des Jahres 1924 den Zweck des Opfertodes in der „Freiheit“, der „deutsche[n] Größe“ und „Ehre“ sahen ${ }^{165}$.

In ungefähr der Hälfte der Fälle präzisierten die Redner, die Gefallenen hätten Deutschland verteidigt und vor einem Krieg auf deutschem Boden bewahrt ${ }^{166}$. Stadtpfarrer Esenwein fasste diesen Gedanken zum Beispiel im Jahr 1930 in folgende Worte: „Sie haben sich als eine schützende Mauer vor die Heimat gestellt und sie vor Schwerstem behütet. Sie haben draußen Unsagbares erduldet, damit wir in der Heimat von den unmittelbaren Greueln des Krieges verschont blieben. ${ }^{\text {“167 In- }}$ dem die Redner eine deutsche Verantwortung für den Ausbruch des Kriegs ablehnten, folgten sie der Überzeugung der meisten Deutschen, die die Gültigkeit des Artikels 231 des Versailler Friedensvertrags nicht akzeptierten ${ }^{168}$. In diesem Zusammenhang wurde auch zweimal explizit auf die sogenannte ,Kriegsschuldlüge verwiesen ${ }^{169}$, ein in erster Linie von der antirepublikanischen Rechten instrumentalisierter Begriff ${ }^{170}$.

Grundbegriffe. Historisches Lexikon zur politisch-sozialen Sprache in Deutschland, Bd.7, Stuttgart 1992, S. 141-431, hier S. 389-393.

163 Ebd.

164 Dieses Feuer kann als Symbol der Vaterlandsliebe gedeutet werden; vgl. LuRz (wie Anm. 5) S. 248-249. Eine solche Deutung unternimmt auch die Presse, die die Schalen als „Opferschalen“ (Staatsanzeiger für Württemberg vom 26.11.1928 und vom 25.11.1929) und das Feuer als „Symbol der sich selbst verzehrenden Liebe“ (Deutsches Volksblatt vom 23.11.1931) bezeichnet.

165 Mauch (Süddeutsche Zeitung vom 4.8.1924); Schwenk (Deutsches Volksblatt vom 4.8.1924).

166 Der Gedanke findet sich z.B. bei Mayer-List: „[...] viel schlimmer wäre heute unsere Lage, wenn sie nicht als lebendiges Bollwerk einst das Vaterland geschützt hätten“ (Deutsches Volksblatt vom 25.11.1929). Die Idee wird ähnlich formuliert von Fleck (Schwäbische Kronik des Schwäbischen Merkurs vom 25.10.1926), Schaal (Staatsanzeiger für Württemberg vom 21.11.1927; Schwäbische Kronik des Schwäbischen Merkurs vom 21.11.1927), Spohn (Amtsblatt der Stadt Stuttgart vom 27.11.1928) und Rau (Amtsblatt der Stadt Stuttgart vom 24.11.1931).

167 Esenwein (Staatsanzeiger für Württemberg vom 26.11.1930).

168 Vgl. Коlв/Schumann (wie Anm. 103) S. 32-33.

169 Mauch: „Deutschlands Ehre unter den Völkern wird mit Füßen getreten, nicht ohne unsere eigene Schuld. Kriegsschuldlüge, ehrloses Verhalten vieler Deutschen den Ausländern gegenüber [...]“; Süddeutsche Zeitung vom 4.8.1924; Stadtdekan Monsignore Rau: „[...] nicht Schuld, deren uns die Feinde so ungerecht geziehen haben“; Amtsblatt der Stadt Stuttgart vom 24.11.1931.

170 Vgl. Kolb/Schumann (wie Anm. 103) S. 38-39. 
Viele Redner betonten, dass die Gedächtnisfeiern ein notwendiger „Akt höchster Dankbarkeit “171 für das Opfer der Gefallenen seien ${ }^{172}$. Die Erinnerung an sie müsse für alle Zeit fortdauern, denn die Toten dürften niemals vergessen werden ${ }^{173}$. Stadtpfarrer Fleck wählte für diesen Gedankengang eine besonders eindringliche Bildsprache: „[...] nie wird kommen der Tag, da man die vergisst, die sich für den Schutz der Heimat und das Wohl des deutschen Vaterlandes eingesetzt haben. Und sollte dieser Tag je kommen, dann soll man dem deutschen Vaterland das Grab schäufeln und ihm noch ins Grab die Schaufel nachwerfen. “174 Die Gefallenen wurden ob ihrer Opferbereitschaft nicht selten zum Vorbild der Lebenden erhoben ${ }^{175}$. So ließ zum Beispiel Kaplan Vogt anlässlich der Gedenkfeier 1919 die Gefallenen sprechen: „Sie rufen uns zu: Nehmt es ernst mit dem Leben! Des Lebens Ernst ist nicht Freude und Genuß, sondern treue Pflichterfüllung. “176 Hier zeigen sich deutlich Tendenzen, Opferbereitschaft zum Selbstzweck zu stilisieren ${ }^{177}$.

Die Vorstellung des Opfertodes der Gefallenen wurde sehr häufig religiös gedeutet. Die Dominanz der Geistlichen in der Rednerfunktion führte zu einer Interpretation des Soldatentodes, in deren Mittelpunkt die Analogie zwischen der als vorbildlich bezeichneten Opferbereitschaft der Soldaten und dem Leidensweg Christi stand. Ein häufiges rhetorisches Mittel, das vor allem von katholischer Seite verwendet wurde, bestand darin, die Gefallenen des Kriegs mit Jesus Christus oder mit Kirchenheiligen zu vergleichen: Die Pfarrer verknüpften die Opferbereitschaft der Gefallenen gedanklich mit dem Opfer des Apostels Paulus ${ }^{178}$, der heiligen Elisabeth von Thüringen ${ }^{179}$ und mit dem Sterben von Christus ${ }^{180}$ und seiner „Opfertat vom Kreuzaltar auf Golgatha“181. Die einzige Verwendung dieses Stilmittels von Seiten eines evangelischen Pfarrers wirkt besonders eigenwillig: Stadtpfarrer Dr. Walter nahm das Zusammentreffen der städtischen Gedenkfeier mit dem Reformationstag am 31. Oktober 1920 zum Anlass, eine Parallele zwischen Jesus Christus,

${ }^{171}$ Mayer-List (Staatsanzeiger für Württemberg vom 25.11.1929).

172 Diese Idee wird ähnlich formuliert von Spohn (Amtsblatt der Stadt Stuttgart vom 27.11.1928), Schaal (Staatsanzeiger für Württemberg vom 21.11.1927; Schwäbische Kronik des Schwäbischen Merkurs vom 21.11.1927) und Dr. Dollinger (Schwäbische Tagwacht vom 1.11.1920)

173 Z. B. Traub: „Zum Untergang reif ist ein Volk, das seine Toten vergisst. Darum heißen Dank “; Stuttgarter Neues Tagblatt vom 24.11.1919, Morgenausgabe.

${ }^{174}$ Schwäbische Kronik des Schwäbischen Merkurs vom 25.10.1926.

175 Z. B. bei Bentele (Württemberger Zeitung vom 24.10.1921), Esenwein ( Staatsanzeiger für Württemberg vom 26.11.1930) und Dr. Dollinger (Schwäbische Tagwacht vom 1.11.1920).

176 Vogt (Stuttgarter Neues Tagblatt vom 24.11.1919, Morgenausgabe).

177 Vgl. Sabine Behrenbeck, Heldenkult und Opfermythos. Mechanismen der Kriegsbegeisterung 1918-1945, in: Kriegsbegeisterung und mentale Kriegsvorbereitung, hg. von Marcel van Der Linden/Gottfried Mergner, Berlin 1991, S. 143-159, hier S. 149-150.

178 Spohn (Amtsblatt der Stadt Stuttgart vom 27.11.1928).

179 Rau (Amtsblatt der Stadt Stuttgart vom 24.11.1931).

180 Spohn (Amtsblatt der Stadt Stuttgart vom 27.11.1928).

181 Schwenk (Deutsches Volksblatt vom 4.8.1924). 
Martin Luther und den gefallenen Helden des Weltkriegs zu ziehen ${ }^{182}$. Ein wiederkehrender Gedanke in diesem Zusammenhang war der, dass das Blut der Gefallenen die Saat zu einer besseren Ernte sei, wobei Assoziationen an christliche Märtyrer mitschwangen ${ }^{183}$. Diese religiöse Deutung wurde durch die christlichen Stilelemente verstärkt, die sowohl das Ehrenmal als auch den Platz um das große Friedhofskreuz prägten. Mithilfe dieses christlichen Opfermythos und seiner inhärenten Hoffnung auf Auferstehung, konnte der Schrecken des Todes gemildert werden ${ }^{184}$. George Mosse zufolge war der christliche Opfermythos Teil eines „Mythologisierungsprozesses“, der zwar Trost spendete, jedoch die Schrecken des Kriegs verschleierte und dadurch eine erneute Kriegsbegeisterung ermöglichte ${ }^{185}$.

Mit dem Gedanken des Opfers eng verflochten war die Überzeugung, die Toten hätten eine Botschaft an die Lebenden. Würde diese Botschaft befolgt, so die Grundlogik vieler Reden, dann wäre das Opfer der Gefallenen nicht vergebens. Der Aufbau dieser Argumentation war dabei diachron: Das Opfer in der Vergangenheit, von den Lebenden der Gegenwart respektiert, würde zu einer besseren Zukunft führen. Die Gegenwart wurde in den Reden allgemein pessimistisch geschildert: Man lebe in einer „Zeit der größten Not"186, in einer „trüben Gegenwart" ${ }^{\text {187 }}$ und reibe sich an „Stachelzäunen von schweren Zeitsorgen und Zeitnöten“188 wund. Für diese gegenwärtige Notlage machten die Redner an äußeren Faktoren die Unfreiheit Deutschlands verantwortlich ${ }^{189}$, wobei drastische Formulierungen, etwa die Deutschen lebten als „Sklavenvolk“190 und in „schmachvoller Knechtschaft “"191 Ausnahmen blieben. Die Redner thematisierten außerdem die „wirtschaftlichen und sozialen Nöte“192 Deutschlands und verwiesen auf die „furchtbare Arbeitslosigkeit“193. An inneren Faktoren beklagten sie den moralischen Verfall ${ }^{194}$ und die Zerrissenheit der Deutschen ${ }^{195}$.

182 Dr. Walter (Stuttgarter Neues Tagblatt vom 1.11.1920, Abendausgabe).

183 Vgl. Latzel (wie Anm. 2) S. 66.

184 Vgl. hierzu: Mosse, Kriegserinnerung (wie Anm. 4) S. 31; Behrenbeck (wie Anm. 177) S. $146-150$.

185 Mosse, Gefallen (wie Anm. 4) S. 42-43, 98-99; Ders., Kriegserinnerung (wie Anm. 4)

S. 31.

186 Traub (Stuttgarter Neues Tagblatt vom 24.11.1919, Morgenausgabe).

187 Ernst (Stuttgarter Neues Tagblatt vom 16.7.1923, Abendausgabe).

188 Schwenk (Deutsches Volksblatt vom 4.8.1924).

189 Esenwein (Staatsanzeiger für Württemberg vom 26.11.1930).

190 Mauch (Süddeutsche Zeitung vom 4.8.1924).

191 Ernst, zitiert in: Lurz (wie Anm. 5) S. 225.

192 Esenwein (Staatsanzeiger für Württemberg vom 26.11.1930).

193 Ebd.

194 Mayer-List (Deutsches Volksblatt vom 25.11.1929); Esenwein (Staatsanzeiger für Württemberg vom 26.11.1930).

195 Schaal: „Zwist und Unfriede [...] der - Gott seis geklagt - am Mark unseres Volkes zehrt“; Staatsanzeiger für Württemberg vom 21.11.1927; die Idee findet sich auch bei Divisionspfarrer Schwenk (Deutsches Volksblatt vom 4.8.1924). 
Als wichtigste Botschaft der Gefallenen an die Zeitgenossen wurde deshalb die Aufforderung zur Einigkeit genannt ${ }^{196}$, ein charakteristisches Element jedes Totenkults ${ }^{197}$. Der Nachdruck, mit dem diese Botschaft bei den württembergischen Gedenkfeiern geäußert wurde, verweist darüber hinaus auf ein starkes Bedürfnis nach Einigkeit in einer Gesellschaft, die sich als zutiefst gespalten wahrnahm ${ }^{198}$. Nur wenn Deutschland einig sei, so die Überzeugung, könne es zu alter Stärke und einer positiven Zukunft gelangen ${ }^{199}$. Stadtpfarrer Fleck formulierte diese Idee im Jahr 1926 mit den Worten: „Es ist als ob sich uns Totenhände geisterhaft entgegenstreckten und uns ein Testament entgegenhielten: [...] auf zum Wiederaufbau, zum geistigen, sittlichen und materiellen; hadert nicht, zerfleischt euch nicht. Liebet euch.“ ${ }^{200}$ Um die Einheit zu beschwören, wurden die Kriegsjahre teilweise idealisiert. Zu dieser Strategie gehörte die bereits erwähnte Verherrlichung der Frontkameradschaft ${ }^{201}$. In seltenen Fällen wurde auch der ,Geist von $1914^{6202}$ gepriesen, zum Beispiel bei der Rede von Divisionspfarrer Mauch aus dem Jahr 1924: „Wir brauchen wieder den Geist des Jahres 1914: den Geist der Einigkeit aller Volksgenossen, wo es sich um das Vaterland und seine Not handelt [...].“203

Der Rückgriff auf diese Mythen anlässlich der Erinnerungsfeiern verschleierte zumindest teilweise die grausame Realität des Kriegs ${ }^{204}$. Während solche Mythen in vielen Ländern der Zwischenkriegszeit verbreitet waren ${ }^{205}$, so ist doch das nahezu gänzliche Fehlen pazifistischer Äußerungen bei den hier untersuchten Gedächt-

196 Rau: „Was tut mehr not in einer solchen Stunde, als dass wir uns wirklich als Brüder zusammentun, dass wir dessen vergessen, was uns trennt und daran denken, was uns einigt, dass wir wirklich voll und ganz ernst machen mit dem Worte: ,Einer für alle, alle für einen“"; Amtsblatt der Stadt Stuttgart vom 24.11.1931; ähnlich auch bei Stadtpfarrer Ernst, zitiert in: Lurz (wie Anm. 5) S. 225 sowie bei Dr. Walter (Schwäbische Tageszeitung vom 2.11.1920) und Traub (Stuttgarter Neues Tagblatt vom 24.11.1919, Morgenausgabe).

197 Vgl. Koselleck, Totenkult (wie Anm. 51) S. 11-12.

198 Vgl. Halbwachs, Topographie (wie Anm. 3) S. 9. Zur Krise der Weimarer Zeit vgl.: Detlev Peukert, Die Weimarer Republik: Krisenjahre der Klassischen Moderne, Frankfurt a.M. 1987, S. 9-10.

199 Z.B. Schaal: „Aber unsere Toten rufen es uns unablässig zu: Ohne Volksgemeinschaft keine Zukunft, ohne Einigkeit keine Freiheit, ohne Opfer kein Segen! “; Schwäbische Kronik des Schwäbischen Merkurs vom 21.11.1927.

200 Fleck (Schwäbische Kronik des Schwäbischen Merkurs vom 25.10.1926).

201 Vgl. Thomas KüHne, Kameradschaft. Die Soldaten des nationalsozialistischen Krieges und das 20. Jahrhundert, Göttingen 2006, S.30-31.

202 Zum ,Geist von 1914“ vgl.: Reinhard Rürup, Der „Geist von 1914“ in Deutschland. Kriegsbegeisterung und Ideologisierung des Krieges im Ersten Weltkrieg, in: Ansichten vom Krieg. Vergleichende Studien zum Ersten Weltkrieg in Literatur und Gesellschaft, hg. von Bernd Hü PPAuf, Königstein i.T. 1984, S. 1-30; Bessel (wie Anm. 4) S. 125-126.

${ }^{203}$ Mauch (Süddeutsche Zeitung vom 4.8.1924); außerdem bei Schaal (Staatsanzeiger für Württemberg vom 21.11.1927; Schwäbische Kronik des Schwäbischen Merkurs vom 21.11.1927) und Esenwein (Staatsanzeiger für Württemberg vom 26.11.1930).

${ }^{204}$ Vgl. Mosse, Kriegserinnerung (wie Anm. 4) S. 27-32.

205 Ebd. 
nisreden bemerkenswert, vor allem im Vergleich mit den pazifistisch geprägten Gedenkfeiern in Frankreich ${ }^{206}$. Dabei mangelte es in Deutschland in der Weimarer Zeit nicht unbedingt an Frontsoldaten, die durch ihre Erfahrung zu Kriegskritikern geworden wären ${ }^{207}$. Die Tatsache, dass die einstigen Kriegsteilnehmer nicht selbst den öffentlichen Raum des Erinnerungsdiskurses nutzten, war möglicherweise ein Grund dafür, dass kriegskritische Überzeugungen keine öffentliche Verbreitung fanden. Die württembergischen Veteranen nahmen weder bei der Organisation der Erinnerungsfeiern noch bei der Rednerrolle eine tragende Rolle ein. Die Struktur der Veteranenverbände als Grund für diese Abwesenheit der Veteranen wurde bereits erörtert. Durch das Fehlen eines nationalen Bezugsrahmens für die Kriegserinnerung wurde dieser Umstand noch verstärkt.

\section{Schlussbetrachtung}

Der regionalgeschichtliche Ansatz hat sich als lohnend erwiesen. Württembergs Alleingang bei der Gesetzgebung zum Gefallenengedenktag ließ eine regionalgeschichtliche Untersuchung zwar zur Notwendigkeit werden, die große Bedeutung des regionalen Rahmens für öffentliche kollektive Deutungsmuster des Ersten Weltkriegs überrascht dennoch. Die Unabhängigkeit Württembergs vom Reich äußerte sich unter anderem darin, dass die Behörden in Stuttgart bereits ab 1919 begannen, eigene Gedenkfeiern zu veranstalten. Ein weiterer Hinweis für Württembergs Eigenständigkeit ist der Umstand, dass der Volksbund Deutsche Kriegsgräberfürsorge, der auf Reichsebene einen nicht unbedeutenden Einfluss auf die Gedenkfeiern des Ersten Weltkriegs ausübte, in Württemberg so gut wie keine Rolle spielte. Die Tatsache, dass die Württemberger den Gedenkfeiern in anderen Teilen des Reiches in der Regel keinerlei Beachtung schenkten, unterstreicht die Abwesenheit eines nationalen Bezugsrahmens für die Kriegserinnerung in Deutschland. Es scheint daher plausibel, dass kollektive Deutungsmuster des Ersten Weltkriegs außerhalb der milieuspezifischen Erinnerungskulturen in Deutschland überhaupt nur auf regionaler Ebene greifbar sind.

${ }^{206}$ In Frankreich ist eine Dominanz der Veteranen bei der Organisation der Gedenkfeiern und bei der Rednerrolle deutlich; vgl. Рrost, Anciens Combattants (wie Anm. 37) S. 5464. Die Behauptung Benjamin Ziemanns, die pazifistische Komponente der Kriegserinnerung in Frankreich könne nicht als zentraler Unterschied zu Deutschland gelten, ist angesichts der Ergebnisse für Württemberg nicht plausibel. Eine starke Einbeziehung der Frauen und der Zivilbevölkerung in den Totenkult, die von Ziemann in Bezug auf die Gestaltung der Kriegerdenkmäler nach dem Ersten Weltkrieg als die zentrale Differenz zwischen Frankreich und Deutschland benannt wurde, konnte bei den württembergischen Gedenkfeiern nicht festgestellt werden; vgl. Ziemann, Milieukulturen (wie Anm. 72) S. 262. Zum Pazifismus der französischen Gedenkfeiern vgl. Prost, Pacifismes (wie Anm. 156) S.12261227.

207 Vgl. Ziemann, Milieukulturen (wie Anm. 72) S. 257. 
Trotz des Fehlens von pazifistischen Elementen bei dem offiziellen Kriegsgedenken kann von einer allgemeinen Kriegsverherrlichung oder Kriegsbegeisterung, die etwa eine direkte Entwicklungslinie zur mentalen Vorbereitung des Zweiten Weltkriegs aufzeigen würden, nicht gesprochen werden. Vielmehr waren die Gedenkfeiern von dem Gefühl der Trauer sowie vor allem von Sinnstiftungsversuchen geprägt, die um die Vorstellung einer Opfertat der Gefallenen kreisten. Diese Vorstellung eines Opfers wurde patriotisch und religiös ausgedeutet und bekam dadurch mythische Qualitäten: Die Vorstellung der Transzendenz des Todes durch die Religion war dominierend, wodurch die Realität des Kriegs verdrängt wurde. In diesem Sinne trugen die Erinnerungsfeiern unmittelbar zur Akzeptanz eines erneuten Kriegs bei.

Inwieweit es sich bei diesen Ergebnissen um spezifisch württembergische Phänomene handelt, kann aufgrund von mangelnden Vergleichsstudien nicht beantwortet werden. Ob die Gedenkfeiern in Stuttgart im Vergleich zu anderen Ländern friedlicher verliefen, zum Beispiel als Folge der relativ stabilen wirtschaftlichen Verhältnisse im Württemberg der Nachkriegszeit ${ }^{208}$ oder ob die Bemühungen um politische Neutralität und die beiden Konfliktjahre 1924 und 1927 im Gegenteil Zeichen einer besonders konfliktreichen Erinnerungskultur in Württemberg sind, muss vorerst unbeantwortet bleiben.

Auch über weitere Zusammenhänge können nur Vermutungen angestellt werden: Es wäre denkbar, dass die religiöse Prägung der Kriegserinnerung in Württemberg mit einem starken Einfluss der Kirche in diesem verhältnismäßig wenig urbanisierten, noch deutlich agrarisch geprägten Land zusammenhängt ${ }^{209}$. Die Unabhängigkeit Württembergs in der Gefallenengedenkfrage und die Festlegung des Gedenktags auf den Totensonntag sind vielleicht ein Hinweis darauf, dass die Gedenkfeiern des Ersten Weltkriegs von älteren regionalen Traditionen des Totenkults beeinflusst waren. Untersuchungen, die vor der Zäsur 1914/18 einsetzen, könnten Klarheit über eventuelle Kontinuitäten geben. Um die These eines regionalen Erinnerungsrahmens zu stützen, wäre eine Untersuchung von lokalen Erinnerungszeremonien und deren Bezug auf die hier untersuchten Gedenkveranstaltungen der offiziellen württembergischen Behörden wünschenswert.

208 Vgl. etwa: Willi Boelcke, Wirtschaftsgeschichte Baden-Württembergs. Von den Römern bis heute, Stuttgart 1987, S. 440-441; Thomas Schnabel, Warum geht es den Schwaben besser? Württemberg in der Weltwirtschaftskrise 1928-1933, in: Die Machtergreifung in Südwestdeutschland. Das Ende der Weimarer Republik in Baden und Württemberg 19281933, hg. von Ders., Stuttgart 1982, S.184-218, hier S.194-195. Zur wirtschaftlichen Entwicklung speziell von Stuttgart und dem Mittleren Neckarraum vgl. Gert Kollmer-von Онеiмв-Loup, Die Entwicklung der Wirtschaftsstruktur am Mittleren Neckar 1800 bis 1950, in: ZWLG 71 (2012) S. 351-382, hier S. 372-382.

209 Vgl. hierzu: SAuer (wie Anm. 9) S. 112, 141-149. 